\title{
Geostrophic Circulation and Heat Flux Across the Flemish Cap, 1988-2000
}

\author{
J. Gil \\ Instituto Español de Oceanografía. C.O. Santander, Promontorio de S. Martín s/n. \\ P. O. Box 240, E-39080, Santander, Spain \\ R. Sánchez \\ CIACOMAR-Universidade do Algarve. Av. 16 Junho s/n. \\ P-8700-311 Olhão, Portugal \\ S. Cerviño and D. Garabana \\ Instituto de Investigacions Mariñas (CSIC). Eduardo Cabello 6, \\ E-36208 Vigo (Spain)
}

Gil, J., R. Sánchez, and S. Cerviño, and D. Garabana. 2004. Geostrophic Circulation and Heat Flux Across the Flemish Cap, 1988-2000. J. Northw. Atl. Fish. Sci., 34: 63-83. doi:10.2960/J.v34.m510

\begin{abstract}
Historical hydrographic data together with data from Spanish bottom trawl surveys are used to estimate geostrophic circulation over Flemish Cap and transport and heat fluxes across the $47^{\circ} \mathrm{N}$ line from 1988 to 2000. The data show a recurrence of anticyclonic circulation on Flemish Cap in July. We conclude that the topography plays a major role in determining the dynamics over the Cap. A coherent cold flow originating in the Labrador Current (LC) skirts around the northeastern flank with geostrophic velocities of $\sim 0.07 \mathrm{~ms}^{-1}$ and partly recirculates around the southern and southwestern flanks of the Cap with a mean flow of $\sim 0.03 \mathrm{~ms}^{-1}$, thereby isolating a central anticyclonic core. This core generally contains warmer and less saline waters than the surrounding waters. The most significant source of variability of the water masses over Flemish Cap is linked to the variability of the advective flows, principally the offshore branch of the LC and oscillations of the north wall of the North Atlantic Current (NAC). The estimated mean northward and southward geostrophic heat fluxes over the Cap across $47^{\circ} \mathrm{N}$ balance to within approximately $10 \%$, although with suggestions of a long-term trend in the net heat flux from positive (northward) in the late-1980s to slightly negative (southward) in the second half of the 1990s. The latter is attributed to an increase in the offshore branch of the Labrador Current over the bank. Linkages between the geostrophic heat fluxes over Flemish Cap and the shift in the Coastal Slope Water System and the NAO are examined. Enhanced Labrador Current flow during 1995-2000 was observed to strengthen the anticyclonic gyre anchored to the topography of the Cap.
\end{abstract}

Key words: climate, Flemish Cap, geostrophy, heat flux, hydrography, NAO

\section{Introduction}

Much of the marine area off eastern Canada is located under the influence of the Labrador Current (LC). The LC, an extension of the Baffin Land Current and the West Greenland Current, transports $\sim 4-11 \mathrm{~Sv}\left(1 \mathrm{~Sv}=10^{6} \mathrm{~m}^{3} \mathrm{~s}^{-1}\right)$ southwards over the continental shelf and along the slope off Labrador and Newfoundland (Petrie and Anderson, 1983; Lazier and Wright, 1993). Over 30\% of the transport of the LC is thought to be barotropic (Greenberg and Petrie, 1988; Petrie and Buckley, 1996). When the LC reaches the northern Grand Banks it divides into two branches (Smith et al., 1937). The inshore branch remains close to the Newfoundland coast flowing south through the Avalon Channel and eventually moves westward after rounding
Cape Race. The offshore branch of the LC carries $\sim 85 \%$ of the transport (Lazier and Wright, 1993) and follows the shelf-break around the Grand Bank. This offshore sub-branch is warmer, deeper and faster than the inshore one. Interannual changes in the offshore branch transport are common and associated with variations in the West Greenland Current (Heywood et al., 1994). On reaching Flemish Pass, the offshore branch further subdivides, with upwards of 6-10 Sv flowing southward through the pass (Petrie and Buckley, 1996). The remainder heads eastward, eventually encircling Flemish Cap (Smith et al., 1937). A schematic cartoon of the circulation is illustrated in Fig. 1.

Climatological analysis shows intense temperature and salinity gradients that delineate a front between cold, 


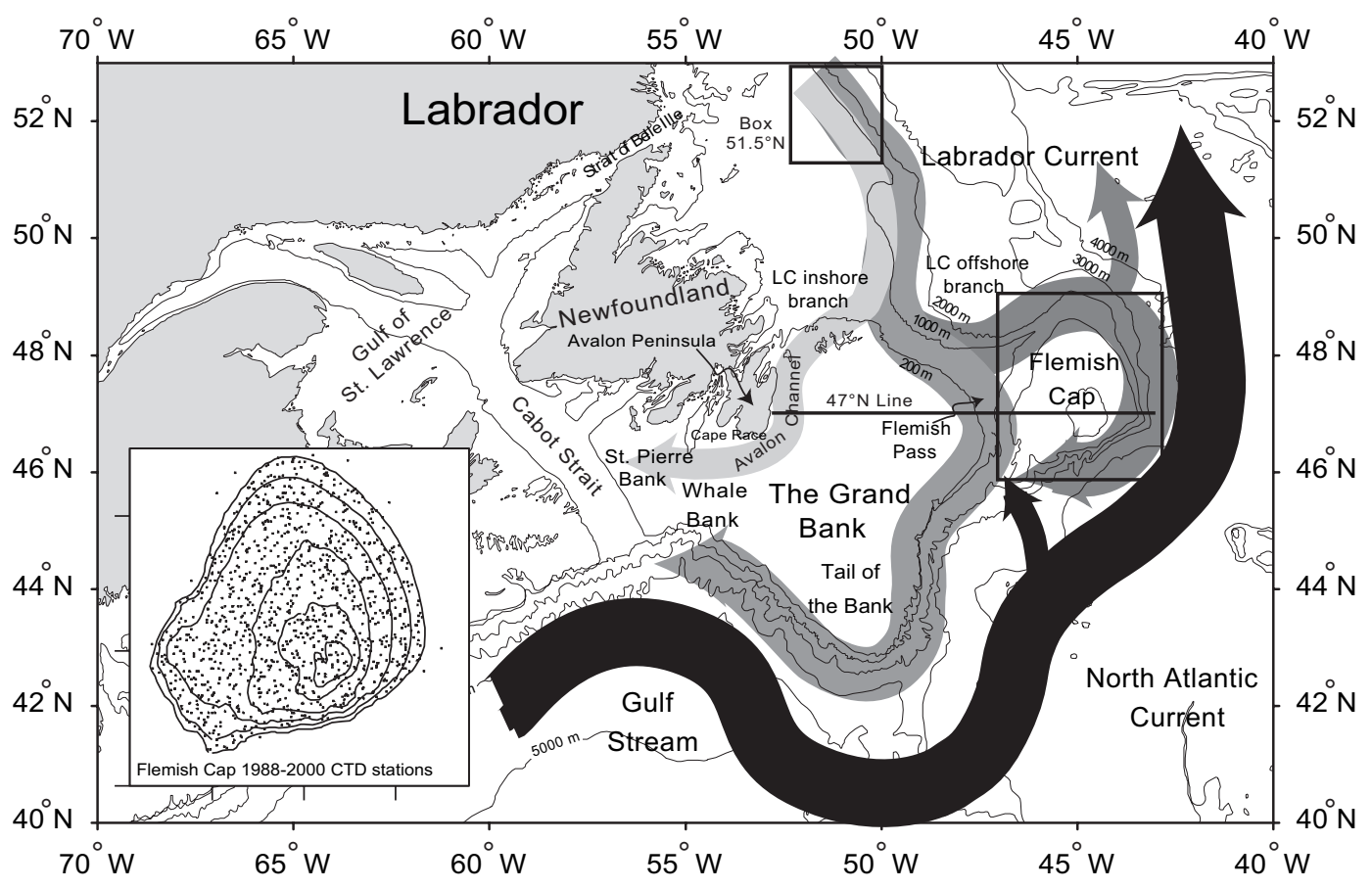

Fig. 1. The Newfoundland Region showing the main bathymetric features and a schematic of the major currents. The $47^{\circ} \mathrm{N}$ line is also indicated. The $51.5^{\circ} \mathrm{N}$ box and the Flemish Cap box refer to the locations where spatial SST means have been presented. Details of the bathymetry of the Flemish Cap and the location of the 1988-2000 CTD stations are presented in the insert in the lower left. Bathymetric lines are $140,180,250,360,550$ and $720 \mathrm{~m}$.

fresh and warm, salty water in the region (Lozier et al., 1995). South of the Grand Bank these gradients mark the boundary between the Slope Water and the northwardflowing Gulf Stream (GS). Around the tail of the Grand Bank the LC and the GS meet giving rise to the North Atlantic Current (NAC) and the NAC front. The NAC carries approximately $30 \mathrm{~Sv}$ of water towards the European basins between Portugal and Greenland, and plays a major role in the regulation of the European climate (Krauss et al., 1987). Further north and east, the hydrographic gradients are preserved by the contrast between the Mixed Water (Worthington, 1976), derived from the southward flow of the Labrador Current, and waters carried by the NAC. Below $300 \mathrm{~m}$, the NAC shows strong convergence near $45^{\circ} \mathrm{N}$ in the vicinity of Flemish Cap, where a southward flowing LC partially feeds into the northward flowing NAC. Lozier et al. (1995) showed that large temperature variability also occurs in this region, which is attributed to strong temporal meandering of the NAC. Several earlier studies pointed out this strong variability in the NAC (Baranov and Ginkul, 1984; Fofonoff and Hendry, 1985), although on average it flows parallel to the $4000 \mathrm{~m}$ isobath (Krauss et al., 1987). The NAC is both strongly affected by topography and baroclinic effects (Heywood et al., 1994). The variability of the current system south of the Subarctic Front seems to be closely related to meanders and eddies near the NAC front (Krauss et al., 1987). Peak values of eddy kinetic energy (EKE) have been found in deep waters $(4000 \mathrm{~m}$ ) from the NAC extension flowing around Flemish Cap (Heywood et al., 1994), suggesting intensive mixing of the waters. Near the Newfoundland Rise, a quasi-permanent meander forces the NAC 100-300 km east of the Cap, with a dynamic low forming between the NAC-LC current systems (Robe, MS 1974), in the middle of which lies Flemish Cap.

Flemish Cap is a plateau of approximately 200 $\mathrm{km}$ radius situated in NAFO Division $3 \mathrm{M}$, centered at $47^{\circ} \mathrm{N} 45^{\circ} \mathrm{W}$ (Fig. 1). It is separated from the Grand Bank of Newfoundland by the approximately $1100 \mathrm{~m}$ deep Flemish Pass, which relatively isolates Flemish Cap (Akenhead, 1986; Colbourne, MS 1997; Gil et al., MS 1998). Bathymetry ranges between $125 \mathrm{~m}$ in the central part of the bank and $700 \mathrm{~m}$ around its edge. The characteristic slope is very steep on the southern half of the plateau, where the depth increases from 200 to 1000 $\mathrm{m}$ over a distance of $30 \mathrm{~km}$, whereas the slope increases more gradually farther north before reaching Flemish Pass. Flemish Cap is located within an area of transition between cold subpolar waters, influenced by fluctuations 
in the LC and warm temperate waters, influenced by fluctuations in the NAC to the south. Labrador Current Slope Water (LCSW) flows from the north with temperatures $<2^{\circ} \mathrm{C}$ and salinity $<34.3$, and North Atlantic Current Water (NACW) flows from the south with temperatures $>4^{\circ} \mathrm{C}$ and salinity $>34.8$. The NAC and LC are topographically constrained by the Grand Bank (Robe, MS 1974).

Previous studies based either on geostrophy (Kudlo and Borokov, MS 1975; Robe, MS 1974; Borokov and Kudlo, MS 1981), drifting buoys (Ross, 1981) or ADCP measurements (Colbourne and Foote, 2000) show that anticyclonic circulation is a quasi-permanent feature over Flemish Cap. The anticyclonic vortex appears as a topographically generated Taylor column over the bank, as shown theoretically (Huppert, 1975; Huppert and Bryan, 1976) and experimentally (Taylor, 1923; Davis, 1972). Average current speeds of $0.1 \mathrm{~ms}^{-1}$ and a nominal width of the anticyclone of $200 \mathrm{~km}$ have been reported (e.g. Colbourne and Foote, 2000). From hydrographic measurements made in 1977-82, Kudlo et al. (1984) reported four patterns of geostrophic flow, of which the most common (67\% of the time) was an anticyclonic eddy following quiescent winds. The passage of major storm events broke down the vertical stratification and contributed to gyre attenuation. The appearance of meandering flows across the Cap leads to a series of intermediate dynamic situations.

Waters over Flemish Cap are often referred to as mixed waters of LC and NAC, modified by retention within the anticyclonic circulation around the bank (Hayes et al., MS 1977; Anderson, 1984). Several papers report the existence of subsurface temperature minima below the summer thermocline (Karasyev, MS 1962; Templeman, MS 1974; Colbourne, MS 1993, MS 1995, MS 1996 and MS 1997; Cerviño and Prego, MS 1997; Gil et al., MS 1998), associated with seasonal thermohaline fronts and emergence of the LC. Akenhead (1986) provided evidence that the LC was the sole source of water within the upper $100 \mathrm{~m}$ range on the Cap itself but the importance of accounting for the influence of both LC and NAC was put forward by Greenberg and Petrie (1988). Their barotropic model, based only upon the LC, underestimated the strength of the clockwise circulation over Flemish Cap. This led them to postulate that the dynamics of the frontal system associated with the confluence of warm and cold waters as the driving mechanism that determines circulation dynamics in the region.

\section{Methods}

Climatological maps are presented based on individual hydrographic stations taken along transects across the Grand Bank of Newfoundland from 1900-98. The data were obtained from the World Ocean Database 1998, version 2.0, January 2000, prepared by the Ocean Climate Laboratory from the National Oceanographic Data Center (NODC, 2000). In order to evaluate mean summer conditions, only profiles acquired between June-August were included. Data were quality-controlled to eliminate erroneous data. Data processing protocol basically followed Lozier et al. (1995). First, a range check as a function of depth was applied and values outside broad property ranges were eliminated. The temperature-salinity $(\mathrm{T}-\mathrm{S})$ curve was approximated by subdividing the observed points into density bins for which the mean $\mathrm{T}-\mathrm{S}$ relation was approximately linear. The standard deviation of the observations was computed for each bin. T-S scatter plots for all stations were constructed. These plots graphically showed data points that deviated significantly from the mean line. Only points that lay within \pm 2.3 standard deviations of the mean were retained as acceptable observations. This limit was chosen on the statistical basis that $\sim 98 \%$ of all observations in a normally distributed population fall within 2.3 standard deviations on either side of the mean (e.g. Lozier et al., 1995).

Monthly, optimally interpolated SST (OISST, source: http://ingrid.Ideo.columbia.edu/SOURCES/. IGOSS/.nmc/.monthly/) data were used to create monthly time series of SST anomalies (with respect to the 1981-2000 mean) from July 1988 to July 2000 at various locations in the western North Atlantic.

Hydrographic data were obtained with Seabird Electronics (SBE) CTDs (Models SBE19 and SBE25) during the series of annual Spanish bottom-trawl surveys carried out on Flemish Cap on board R/V Cornide de Saavedra in July from 1988-2000. Cruises were between 10-15 days duration with approximately 110 sampling stations per cruise. The mean station separation was approximately $18.5 \mathrm{~km}$ although stations were randomly stratified in a spiral track from the borders towards the center, following standard methods described in Vázquez (MS 2000). Annual reports of the hydrographic conditions in Flemish Cap as observed during these surveys are available at www.nafo.int/publications. Data from 1992 and 1994 were not accessible because of file corruption. A total of 1296 stations were included (see inset in Fig. 1). For each station, the data were linearly interpolated to every $10 \mathrm{~m}$ in the vertical. Data also were objectively analyzed onto a horizontal grid using a simple isotropic univariate interpolation method. The objective technique, with scale separation developed by Doswell (1977) and Maddox (1980) and using the filtering properties of the objective analysis scheme given by Barnes (1964), was applied. It was based 
on neighboring data and a correlation scale of $15 \mathrm{~km}$ (twice the Rossby deformation radius for surface structures in the area) while the number of interpolations was set to 70 to permit an error variance $0(0.05)$ that accounted for previous smoothing of the observations. Additionally, the analysis operated as a low-pass filter, filtering the observed data field to define the analyzed field. The band-pass response of filtering was centered at a wavelength of $40 \mathrm{~km}$, imposed by the mean distance between stations. The short wavelength noise was therefore filtered out. The result was a gridded matrix with $0.07^{\circ}$ longitude by $0.05^{\circ}$ latitude $\left(8 \times 4 \mathrm{~km}^{2}\right)$ cells, vertically interpolated every $10 \mathrm{~m}$.

Dynamic calculations, based upon the dynamic topography field, were computed using a 200 dbar reference level, similar to previous studies (e.g. Kudlo and Burmakin, MS 1972; Kudlo and Borovkov, MS 1975; Kudlo et al, 1984). The magnitude of interannual variations in the strength of the circulation across Flemish Cap was computed from the near-synoptic July measurements on the standard transect along $47^{\circ} \mathrm{N}$ that crosses over the shallowest part of Flemish Cap. Geostrophic velocity, $\mathrm{T}-\mathrm{S}$ sections, geostrophic transport and heat fluxes were calculated along this line. Anomalies in current flow were estimated, i.e. differences from the long-term (1988-2000) normal. Mean states have been computed based on gridded fields of temperature, salinity and derived quantities from the transect stations along $47^{\circ} \mathrm{N}$. For geostrophic velocity calculations along this line, dynamic topography was computed at all depths with the reference at $200 \mathrm{~m}$ or the bottom if at a lesser depth. The time varying part of the geostrophic velocity field $\left(v^{\prime}(x, z)\right)$ was computed by subtracting the average velocity distribution along $47^{\circ} \mathrm{N}$ from a section observed during any single cruise $\left(v_{s}\right)$. The averaging period was again 1988-2000. Geostrophic transports were computed along $47^{\circ} \mathrm{N}$ integrating the velocity structure according to the algorithm presented by UNESCO (1991):

$$
G T=L \int_{Z_{n}}^{z_{o}}\left(v-v_{s}\right) d z
$$

where $L$ is the distance between two stations in meters.

The temperature $\left(T^{\prime}(x, z)\right)$ and salinity $\left(S^{\prime}(x, z)\right)$ anomaly fields were similarly computed. Thus we were also able to compute the time varying part of the heat flux $\left(H^{\prime}\right)$ in a way similar to Freeland (2002):

$$
H^{\prime}=p \cdot C_{p} \iint v^{\prime}(x, z) \cdot T^{\prime}(x, z) \cdot d x d z
$$

where $C_{p}$ is the specific heat and $\rho$ the mean density of seawater. Finally, the absolute heat fluxes are presented by adding the mean heat flux to $H^{\prime}$.

\section{Results}

\section{Climatological analysis}

Along $47^{\circ} \mathrm{N}$ the summer climatology shows that the area east of Newfoundland is characterized by an intense front between cold, fresh and warm, salty water that extends from the surface to $>200 \mathrm{~m}$ at $\sim 47^{\circ} \mathrm{W}$ (Fig. 2). Warmer and saline NAC waters typify the area off the slope of the Grand Banks, whereas shelf regions west of $47^{\circ} \mathrm{W}$ are occupied by colder, low salinity LC water. Below $300 \mathrm{~m}$, the NAC shows convergence in the vicinity of Flemish Cap, as observed by the sharp increase in salinity. Isotherms and isohalines tend to follow the bathymetry, supporting topographic control of the climatological flows (Fig. 3). To the southwest of the Grand Banks, these T-S gradients mark a clear boundary between the Slope Water and the Gulf Stream. The particular location and topographic characteristics of Flemish Cap result in the plateau being primarily influenced by the LC, although traces of the NAC are found along the eastern flank of Flemish Cap. Horizontal temperature differences in the climatological means along $47^{\circ} \mathrm{N}$ are $\sim 6^{\circ} \mathrm{C}$ at $200 \mathrm{~km}$ at the sea surface versus more than $9^{\circ} \mathrm{C}$ over the same distance at $100 \mathrm{~m}$. The temperature contrast between slope and offshore waters is sharper at subsurface levels than at the surface.

\section{Temperature and Salinity Sections}

A seasonal thermocline commences in early May and continues through to late August, at which time the maximum surface temperatures may reach $12^{\circ}-13^{\circ} \mathrm{C}$. This seasonal temperature cycle is accompanied by a salinity cycle with low values in summer produced by the combination of the southward advection of the Labrador Current and ice melting on the Labrador and Newfoundland shelves (Colbourne and Foote, 2000). The amplitude of the seasonal cycles of temperature and salinity decrease considerably with depth below $50 \mathrm{~m}$. There is no detectable seasonal cycle below $100 \mathrm{~m}$ (Colbourne and Foote, 2000). Distribution of mean July hydrographic properties along $47^{\circ} \mathrm{N}$ shows a well-developed thermocline partially deepened over the central region of the bank (Fig. 4). Below it, there is a weak horizontal temperature gradient, with maximum values west of $45.5^{\circ} \mathrm{W}$ and minimum temperatures along the easternmost tip. Salinity increases with depth with bowl-shaped salinity contours, indicative of anticyclonic circulation around the periphery of the bank.

The standard deviation maps of thermohaline properties (Fig. 4) show that the major variability occurs in the upper $25 \mathrm{~m}$. Variability diminishes sharply with depth 


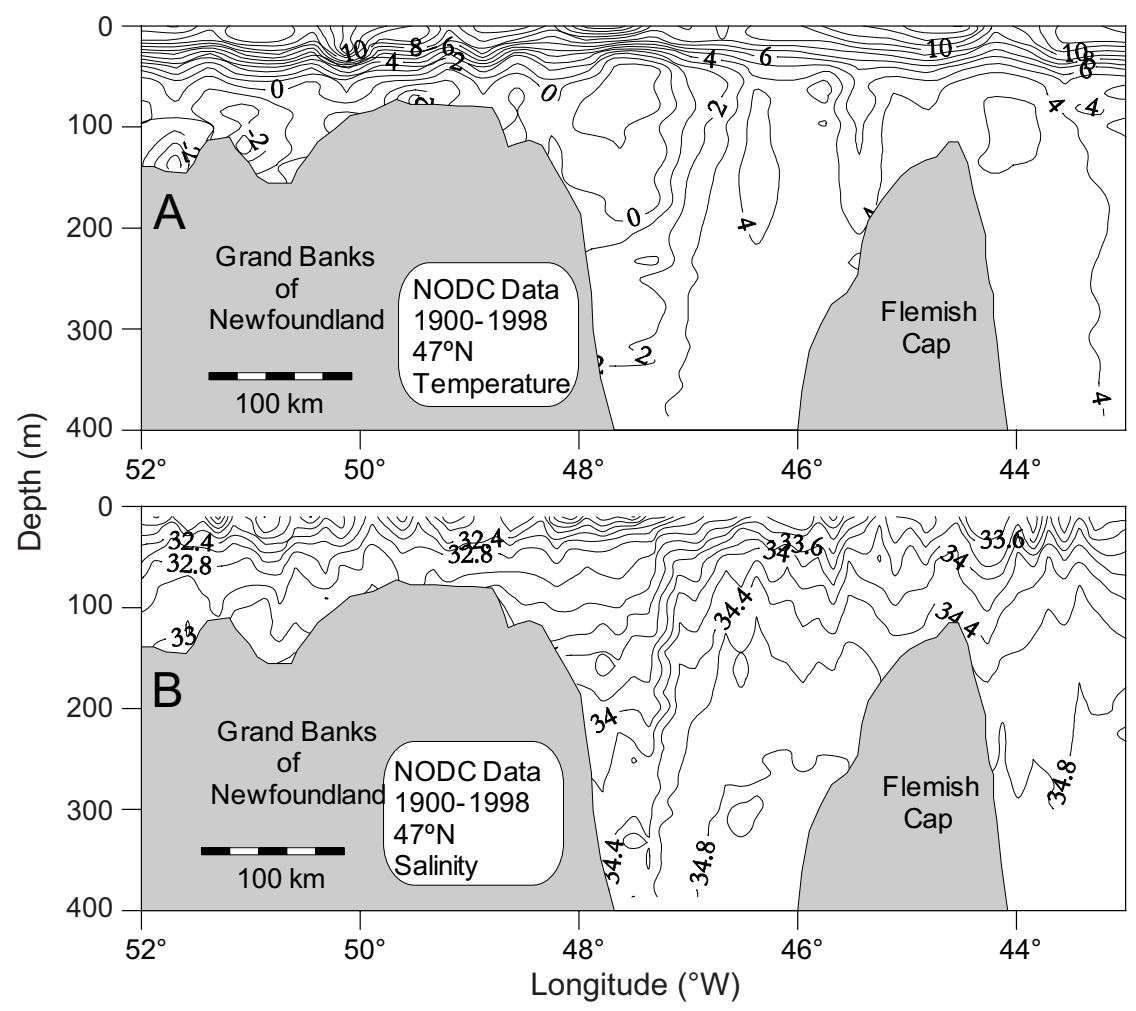

Fig. 2. Climatological transects across the $46^{\circ} \mathrm{N}$ line. (A) Temperature $\left({ }^{\circ} \mathrm{C}\right)$. (B) Salinity. Source: NODC $1900-98$. The deep trough between 46 and $48^{\circ} \mathrm{W}$ is the Flemish Pass.

and below $200 \mathrm{~m}$ the mean values exhibited very little interannual variability. There tends to be a saddle of low variability on the central Cap. Maximum temperature and salinity variability was located at the periphery of the bank, although it was largest on the westernmost side, associated with the northward flow.

\section{Dynamic topography}

The July mean geostrophic velocity field at $10 \mathrm{~m}$ (Fig. 5) shows a coherent anticyclonic flow over Flemish Cap. Maximum velocities occur above the $300-600 \mathrm{~m}$ isobaths. A narrow, intense southward flow is centered between $44-44.5^{\circ} \mathrm{W}$ with geostrophic velocities $\mathrm{O}\left(0.1 \mathrm{~ms}^{-1}\right)$. A wider but less intense northward flow occurs along the westernmost flank. This picture is consistent with the existence of a semi-permanent anticyclonic gyre around the Cap, which tends to isolate the waters on the central region of the Cap. Figure 4 shows the cross section of mean velocities and their standard deviations along the $47^{\circ} \mathrm{N}$ line over the Flemish Cap. Contrary to the variability structure of salinity and temperature fields, it is noteworthy that the largest variability of geostrophic velocities occurs along the easternmost tip, i.e. associated with the southward flow. The northward, return flow seems more stable in terms of velocity structure and temporal variability.

The analysis of the 1988-2000 dynamic topographies shows that although water circulation in July is essentially anticyclonic around Flemish Cap (Fig. 6, 7, and 8), there are significant year-to-year differences. Circulation patterns may be classified into two main types: (i) a well-developed anticyclone gyre with a well-defined core anchored to the top of the bank and (ii) highly variable circulation where the central gyre is poorly defined and there are numerous mesoscale eddies.

Years 1988 and 1989 belong to type (ii), where the finer scale analysis revealed a number of mesoscale eddies distributed over Flemish Cap, although the larger scale pattern showed anticyclonic circulation. In 1990 a blend of types (i) and (ii) occurred, characterized by a clear anticyclonic circulation but neither a definite gyre core nor a coherent surrounding flow were evident. In contrast, during 1991 a well-developed type (i) circulation pattern occurred. A clear central core made up of a number of mesoscale nuclei appeared encircled by anticyclonic 


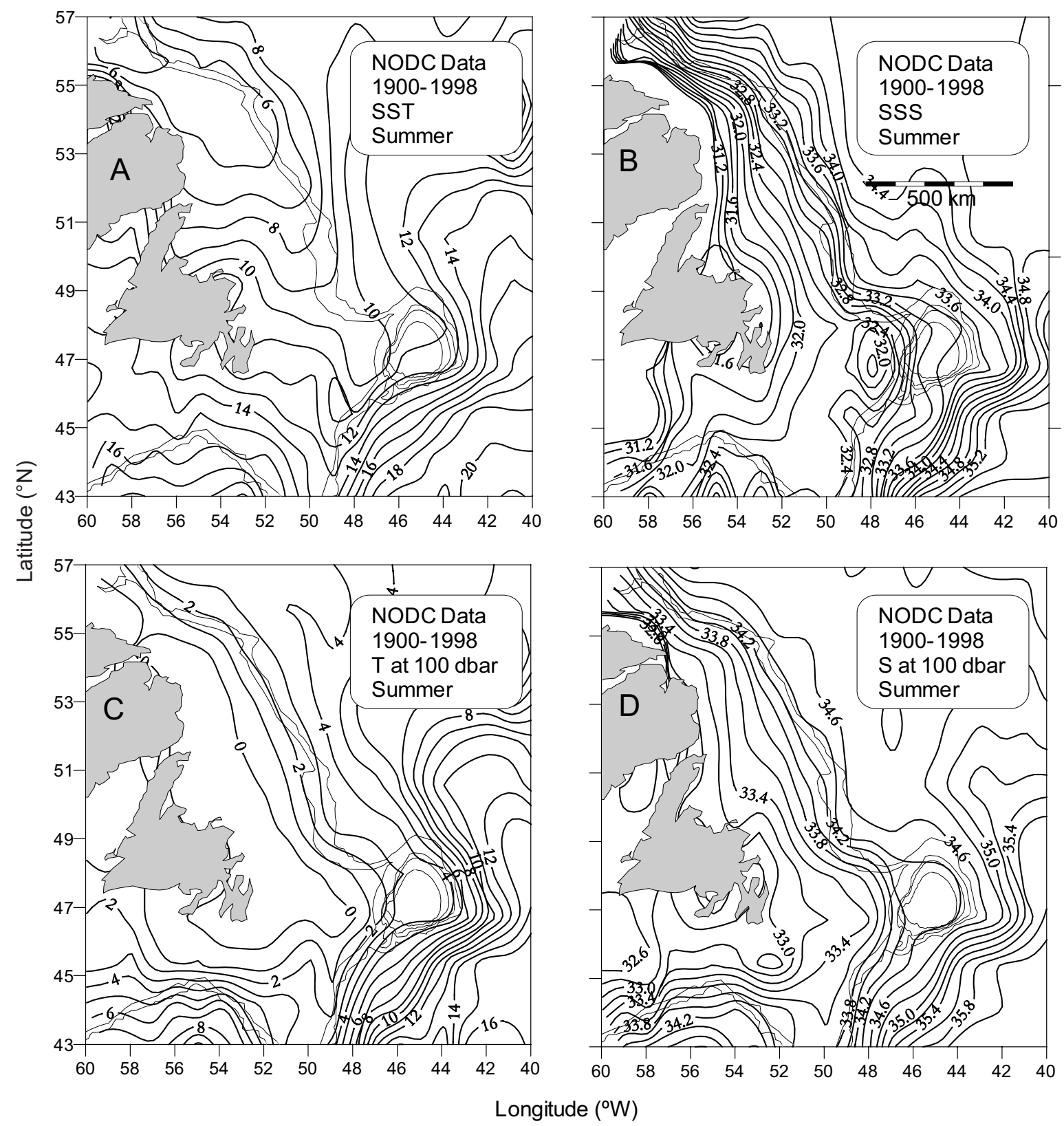

Fig. 3. Climatological plots of temperature $\left({ }^{\circ} \mathrm{C}\right)$ and salinity of the Newfoundland area. $(\mathbf{A})$ and $(\mathbf{B})$ at sea surface; (C) and (D) at $100 \mathrm{dbar}$.

flow. This situation was repeated in 1993, when horizontal gradients through the gyre center were smoother. The next sampled year (1995) was likewise characterized by two large anticyclonic nuclei separated by a relative low over the Cap from northeast to southwest.

In 1996, a coherent anticyclonic circulation encircled a central core in which a number of stations bore approximately the same geopotential anomaly. Conversely, in
1997 the bank's dynamic topography suggested two areas: the northern zone was occupied by relative dynamic lows, whereas the southern one bore the highest dynamic height values. The most feasible hypothesis is that the gyre was displaced southwards and was not fully sampled. In this case, a meandering flow crossed the bank from northwest to southeast, as was observed by Kudlo et al. (1984). The most well defined type (i) gyre was observed in 1998. Anticyclonic circulation was identifiable except in the 

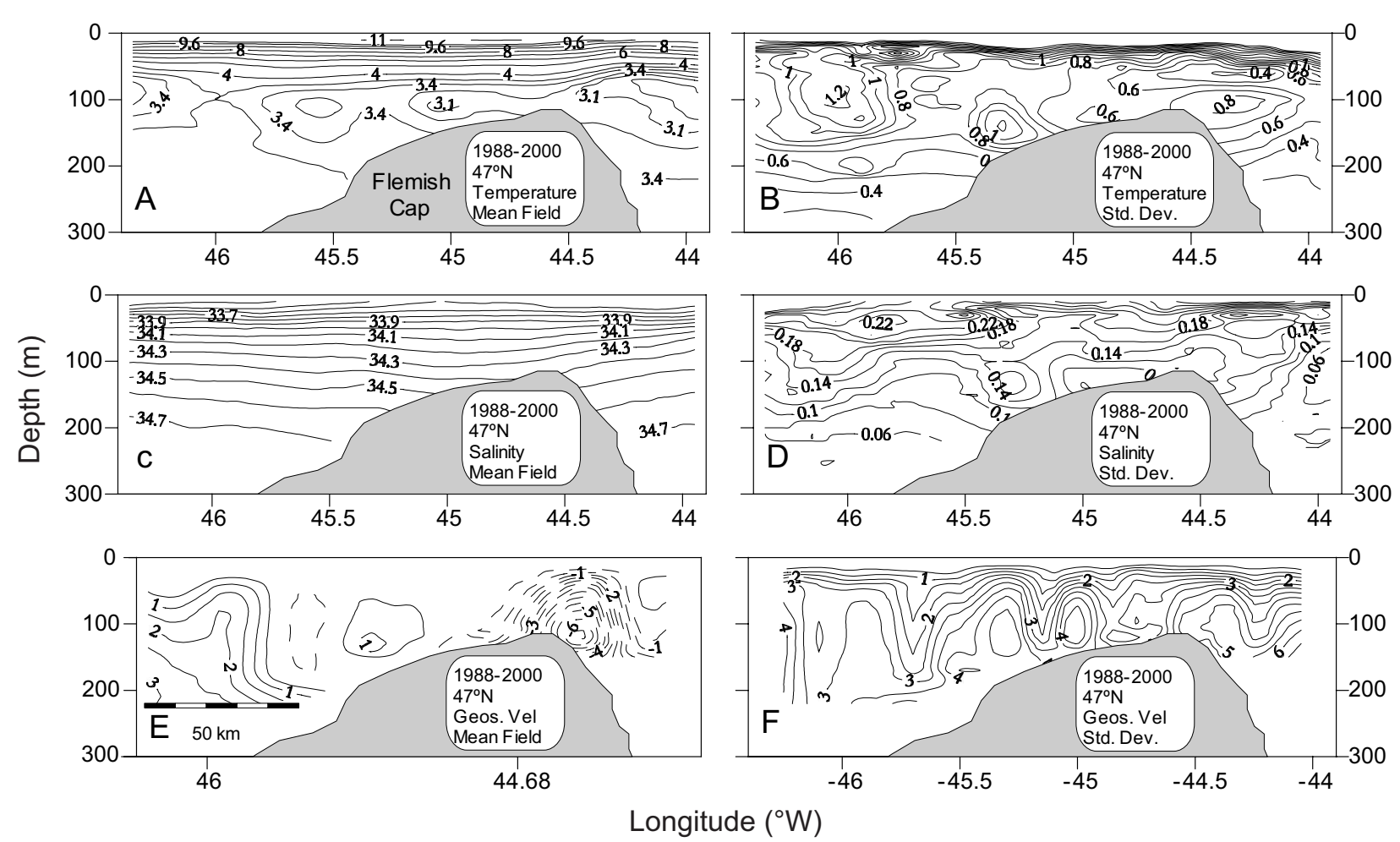

Fig. 4. 1988-2000 mean and standard deviation cross-sections along the $47^{\circ} \mathrm{N}$ line from bottom trawl surveys. (A) and (B) temperature $\left({ }^{\circ} \mathrm{C}\right) ;(\mathbf{C})$ and $(\mathbf{D})$ salinity; $(\mathbf{E})$ and $(\mathbf{F})$ geostrophic velocity $\left(\mathrm{m} \mathrm{s}^{-1}\right)$. Broken lines in Figure $4(\mathbf{E})$ indicate negative (equatorward) velocities.

southeast where a lack of stations prevented us from determining whether the gyre was closed. Of the remaining years, 1999 also showed a large high centered on the top of the bank, surrounded by variable and incoherent lows. A well-developed anticyclonic gyre made up of smaller sub-mesoscale eddies was seen in 2000.

\section{Water Masses and Dynamic Topography}

Water within the anticyclonic gyre on Flemish Cap tends to contain lower salinities than the surrounding waters, especially off the southern flank, where ambient salinity values are influenced by subtropical water masses (Fig. 4). The water masses at 40 and 120 dbar were analyzed in relation to the circulation scheme described in the previous section, and their sources of interannual variability are discussed.

The well-developed anticyclone sampled in July 1991 mirrors temperature and salinity distributions (Fig. 9). The gyre core at $40 \mathrm{dbar}$ contains higher temperatures and lower salinities versus the saltier, colder surroundings. The salinity pattern was maintained down to $120 \mathrm{dbar}$, where a low salinity nucleus coincided with the center of the anticyclone although the temperatures at this depth were colder in the gyre than in the surround waters. The salinity situation occurred again in 1998, yet in this case the core temperature at $120 \mathrm{dbar}$ was more homogeneous $\left(\sim 3.8^{\circ} \mathrm{C}\right)$ and slightly higher than its surroundings (Fig. 10).

The anticyclonic gyre shows variability associated with variations in the source flows that is reflected in the deeper water mass properties. 1991 and 1998 showed strong anticyclonic gyre development. Although middepth temperatures were slightly warmer in 1998 than in 1991, in both years at $220 \mathrm{dbar}$ the westernmost flank bore higher temperatures than elsewhere (Fig. 11).

The bank's location and dimensions play a strong role in determining the physical oceanographic dynamics over Flemish Cap. In addition, the variability in the LC and NAC over Flemish Cap modulate the topographic-steered dynamics over Flemish Cap. Occurrence of NAC-like water masses around the southern plateau's fringe is observed to be a recurrent feature (e.g. Cerviño and Prego, MS 1997; Gil et al., MS 1998; Cerviño et al., 1999). Temperature and salinity plots at $220 \mathrm{dbar}$ in 1988 reveal no obvious anticyclonic gyre (Fig. 12). This situation may correspond to either a weakening of a pre-existing 


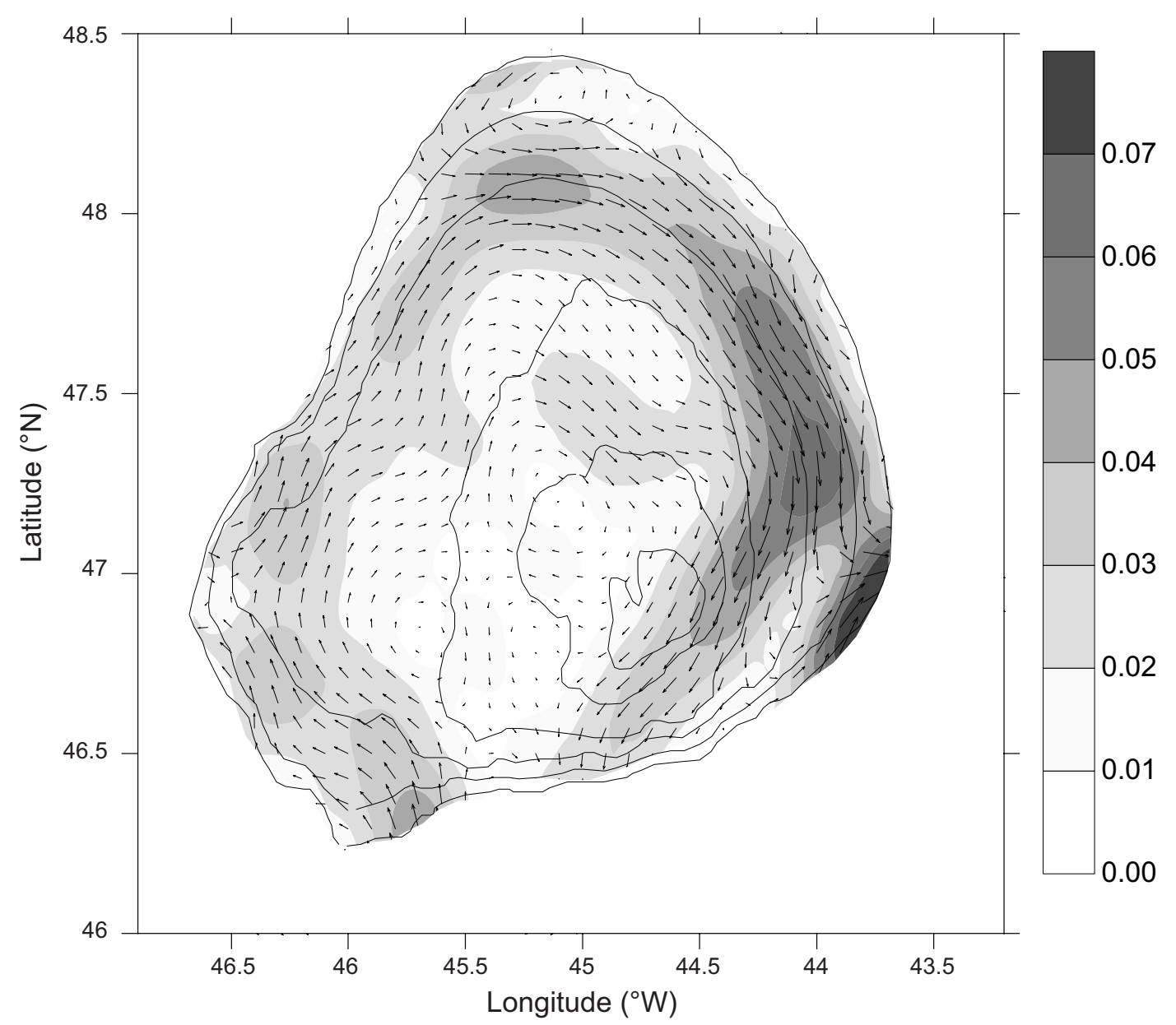

Fig. 5. Flemish Cap mean geostrophic velocity vectors from 1988-2000 July CTD. Shading indicates the amplitude of the geostrophic velocities $\left(\mathrm{ms}^{-1}\right)$.

anticyclonic structure or a weak dynamic situation with relatively stagnated water masses in the form of smallscale nuclei. Around the southwest flank of the bank there is a coherent structure with high temperature and salinity. This suggests the possibility that the poleward-flowing NAC waters may have displaced the anticyclonic gyre to the northeast. In the remaining years characterized by clear anticyclonic circulation (1990, 1993, 1996, 1999, 2000), temperature and salinity distributions follow the general pattern described for 1991 and 1998 (not shown).

In contrast, in 1988 when the situation was characterized by a number of small anticyclonic eddies over the Cap, no consistent salinity signal was associated with any dynamic feature (Fig. 13). At 40 dbar a succession of low and high salinity structures was observed, with mean salinities $\sim 34.1$ and higher salinities $(\sim 34.4)$ to the southwest at subsurface levels (120 dbar). Likewise, temperature distribution at 40 dbar also showed high variability with eddies containing warm $\left(6^{\circ} \mathrm{C}\right)$ and cold $\left(3^{\circ} \mathrm{C}\right)$ nuclei. At $120 \mathrm{dbar}$, intense horizontal temperature gradients were associated with an anomalously warm signal to the southwest $\left(5-6^{\circ} \mathrm{C}\right)$. The situation in 1995 was characterized by an anticyclone interrupted by a relative low through the middle in the northeast-southwest direction. This dynamic picture was mirrored by both the temperature and salinity fields at 40 and 120 dbar, where warm, low salinity waters $(<34.0)$ were separated by a higher salinity, colder water wedge (Fig. 14).

\section{Geostrophic Transports and Heat Flux}

The integration of geostrophic velocities to estimate transports from $10-400 \mathrm{~m}$ along $47^{\circ} \mathrm{N}$ is presented in Fig. 16a. The calculations are restricted (horizontally) to the bank, in an attempt to avoid features outside the bank. The total northward (positive) and southward (negative) baroclinic transports were computed for each year and provide an estimate of the strength of the gyre around the 

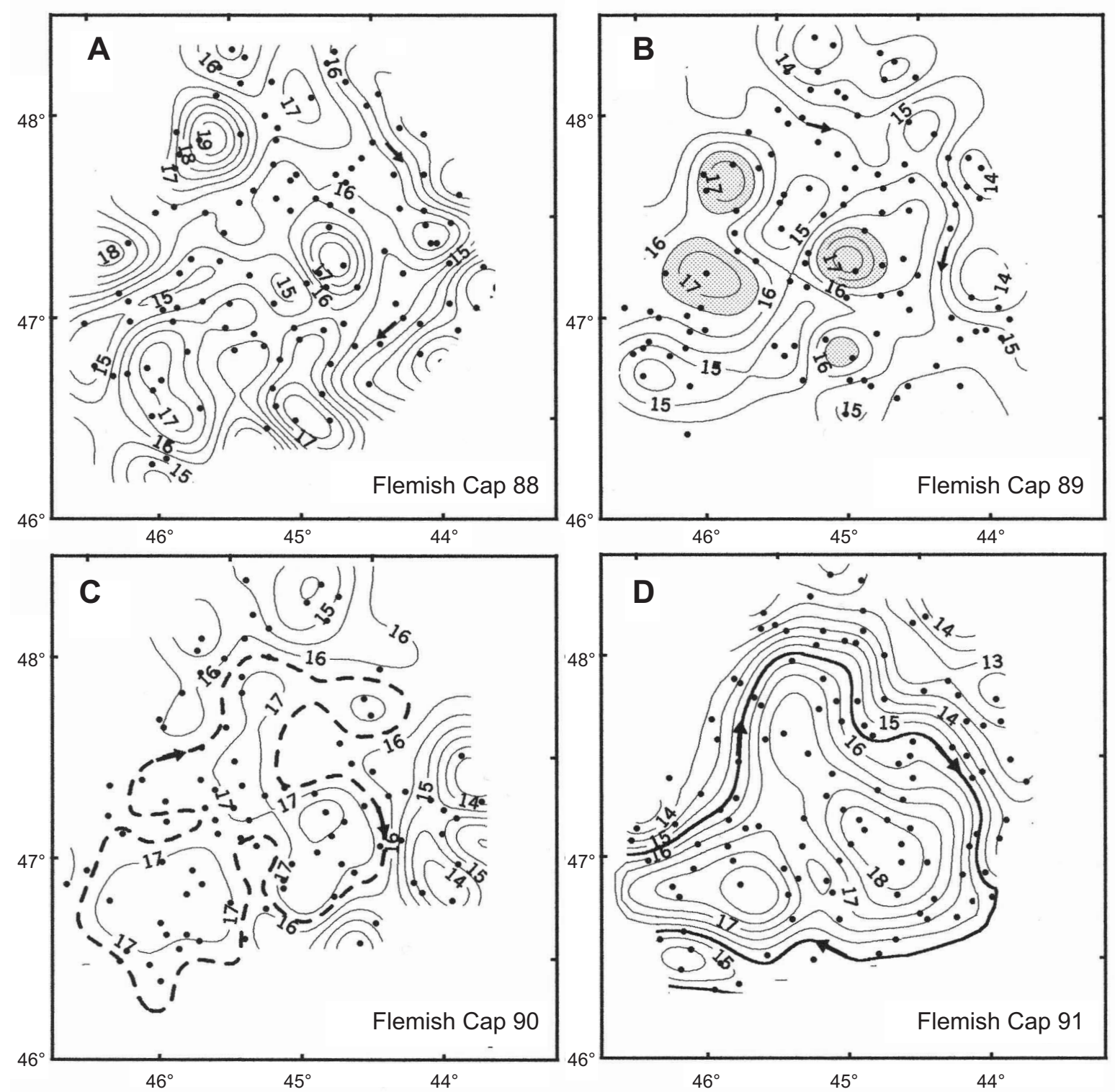

Fig. 6. 1988-2000 series of dynamic topographies (dyn. cm). (A) 1988 (B) 1989 (C) 1990 (D) 1991.

Cap (Colbourne and Foote, 2000). The mean northward and southward transports were $\mathrm{O}(0.3) \mathrm{Sv}$, with the net transport near zero. These results support the existence of a semi-permanent anticyclonic circulation during July. However, there are a number of years when southward transport exceeded the northward flux (1991, 1995, 1996 and 2000). In contrast, in 1997 and 1998 the net volume transport integrated along $47^{\circ} \mathrm{N}$ was directed northwards. The net geostrophic heat flux anomalies are displayed in Fig. 16b. The mean heat fluxes north and south are of order of $2.3 \mathrm{TW}$ (TerraWatts, $10^{12} \mathrm{~W}$ ) with the mean net heat flux approximately $10 \%$ of this value. Contrary to the volume transport estimates, the long-term trend of the heat flux series seems to shift from positive (northward) in the late-1980s to a slightly negative (southward) net heat flux in the second half of the 1990s.

\section{Discussion}

\section{Generation of anticyclonic circulation}

The well-known Taylor-Proudman theorem states that slow steady inviscid flow in a rapidly rotating homogeneous system is independent of the co-ordinates parallel to the rotation axis (Proudman, 1916; Taylor, 1923). Jacobs 

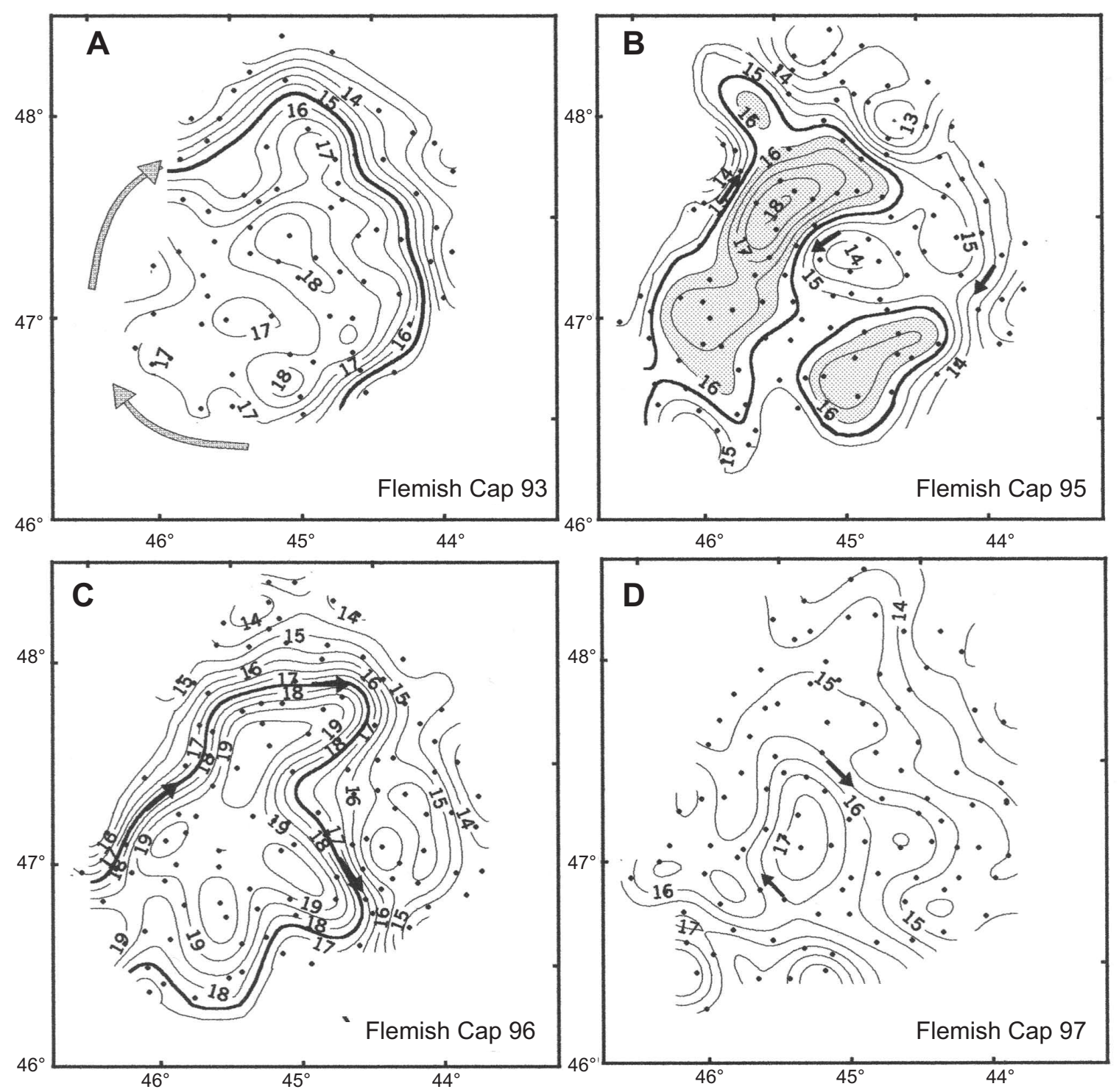

Fig. 7. 1988-2000 series of dynamic topographies (dyn. cm). (A) 1993 (B) 1995 (C) 1996 (D) 1997.

(1964), rather than considering a purely inviscid theoretical flow, introduced a perturbation parameter $p=v / f L^{2}$, where $v$ is the coefficient of kinematic viscosity, $f$ is the Coriolis parameter, and $L$ is the horizontal dimension of the obstacle. Inertial columns are formed when $p$ tends to zero, otherwise viscous columns form. Hogg (1973) parameterized the stratification by $S=g H \Delta \rho / L^{2} f^{2} \rho_{z}$, where $\mathrm{g}$ is the acceleration due to gravity, $\mathrm{H}$ is the fluid depth, $\Delta \rho$ is the density difference over depth $\mathrm{H}$, and $\rho_{z}$ is the average density of the fluid over depth $\mathrm{H}$. S tends to zero as the fluid becomes more homogeneous, and to 1 for a highly stratified fluid. He observed that after a threshold obstacle height was exceeded, a Taylor column was formed for a homogeneous fluid and a conical vortex was formed for a stratified fluid. It was observed that for nearly homogeneous $(S<<1)$ flow with very small Rossby number $(R o$, $R o=\mathrm{U} /(f \cdot L)$ where $\mathrm{U}$ is the depth averaged velocity), the streamline pattern is two-dimensional. This is verified even though the baroclinic component of the flow can be of the same magnitude as the barotopic. Considering the work of Hogg (1973) for $S \sim R o$ and $E k^{1 / 2}<<R o$, a Taylor column could be forced by topography whose height exceeded $\beta R o H$. ( $E k$ is the Ekman number, $E k=v / f H$ and $\beta$ is a parameter dependent upon the obstacle shape). 

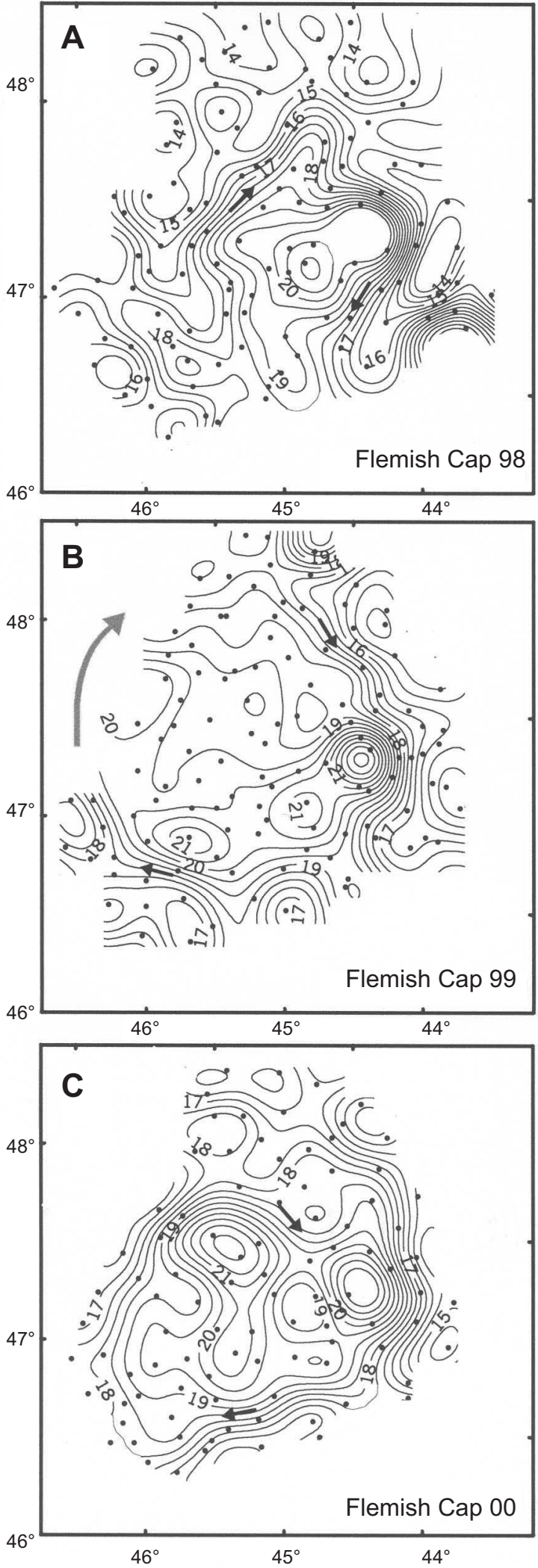

Fig. 8. 1988-2000 series of dynamic topographies (dyn. cm). (A) 1998 (B) 1999 (C) 2000.
Huppert (1975) compared the effects that occur in homogeneous flows with those that occur in stratified flows. He parameterized the stratification by $B=N H /$ $f L$, where $N$ is the buoyancy frequency. For a weakly stratified quasi-geostrophic flow (Ro and $B<<1$ ), vertical obstacles, no matter how low, induced a region of closed streamlines and an associated Taylor column, which are not necessarily present in the flow over a smooth obstacle of comparable height.

The offshore LC branch that skirts around Flemish Cap supplies the source waters for the development of the anticyclonic circulation over Flemish Cap and the Cap is the bathymetric obstacle. We attempted to characterize the flow over the Flemish Cap using a barotropic flow weaker than the baroclinic component $\mathrm{O}\left(0.1-0.2 \mathrm{~ms}^{-1}\right)$, and $R o$ is $\mathrm{O}(0.05-0.1)$. Taking $300 \mathrm{~km}$ as the characteristic $\mathrm{L}$ for the Flemish Cap, $H=4000 \mathrm{~m}, \Delta \rho=2.5 \mathrm{~kg} \mathrm{~m}^{-3}, \rho_{\mathrm{z}}=1027 \mathrm{~kg}$ $\mathrm{m}^{-3}$ and $f=1.04 \times 10^{-4} \mathrm{~s}^{-1}$, then $S \sim 0.1$. The Ekman number is $E k=10^{-13}$. The square root of $E k=3 \times 10^{-7}<<R o$. For summer conditions in the Flemish Cap, $N \sim 10 \mathrm{cph}$ and Huppert's (1975) stratification parameter $B=0.3$, i.e. there is weakly stratified flow. In this case, an abrupt shape could generate Taylor columns. Since the bank represents more of a smooth obstacle with an angle of $\sim 5^{\circ}$, it seems more likely that the homogeneous barotropic component might be responsible for the generation of closed streamlines and consequently the Taylor columns over Flemish Cap.

\section{Heat flux shift}

Could changes in the LC structure and/or its properties be the cause of the shift in the net heat flux pattern across the $47^{\circ} \mathrm{N}$ line? July OI-SST anomalies computed over the whole of Flemish Cap from 1988-2000 show a quasi-decadal cycle (Fig. 17). SST anomalies reached a minimum of $-2^{\circ} \mathrm{C}$ in 1991 , after which they increased steadily to reach $+2^{\circ} \mathrm{C}$ by 1999 . Figure 17 also shows the July mean OI-SST anomalies at a location further north (box at $51.5^{\circ} \mathrm{N}$, see Fig. 1). This box is assumed to be more exposed to LC flows. The similar pattern in both gives a hint that July SST anomalies and the heat flux across the $47^{\circ} \mathrm{N}$ line must be a consequence of the variability of the LC. Negative SST anomalies in the early 1990s contrast with the increase of heat flux from the atmosphere to the ocean observed by Colbourne and Foote (2000). Hence, we propose that advection must be the primary mechanism determining local thermal variability over the Cap, as previously postulated by Colbourne and Foote (2000).

The northward (poleward) heat transport (Fig. 18b) shows no apparent relationship with the OI-SST anomaly. However, an inverse correlation between the southward 

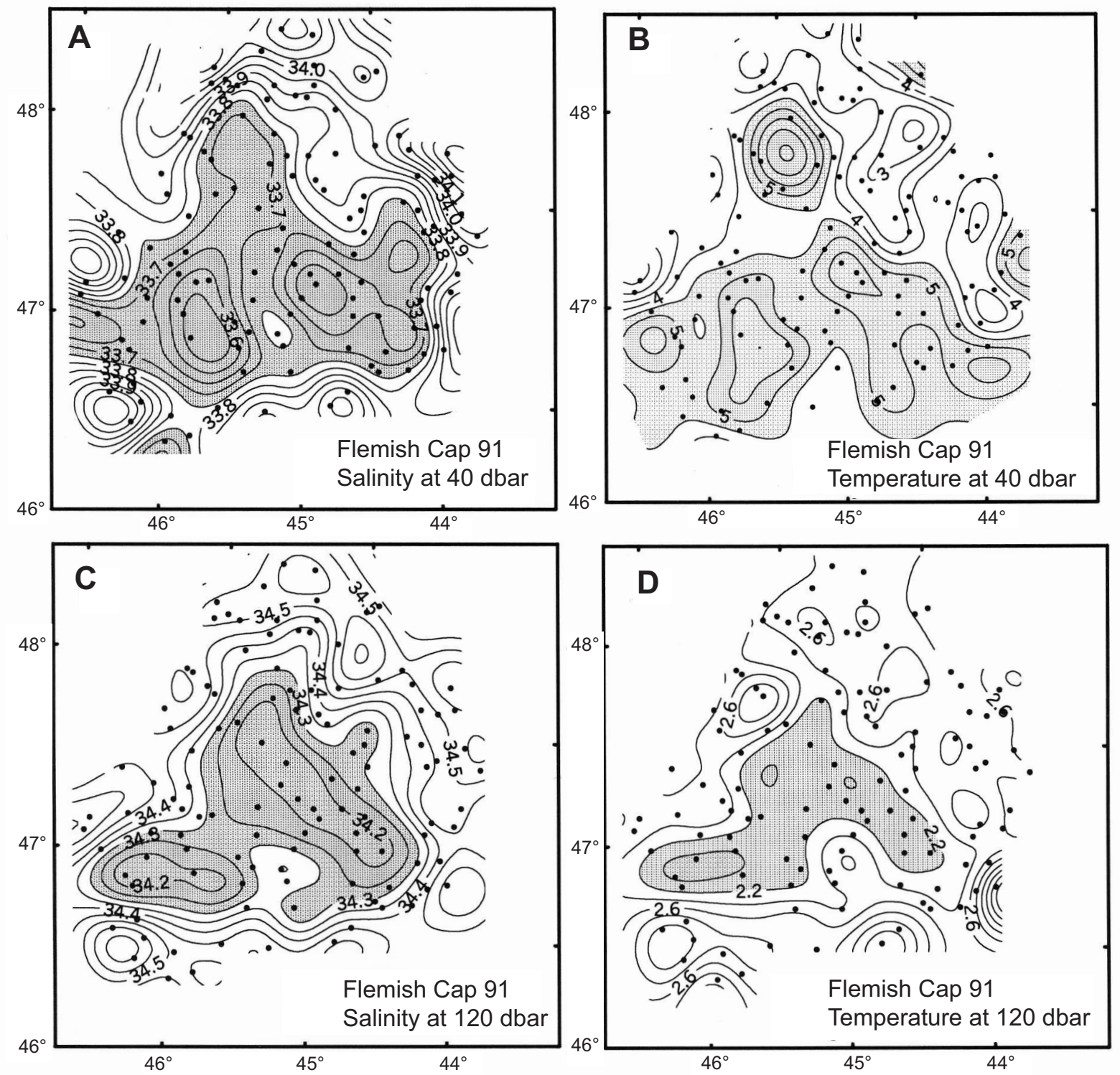

Fig. 9. 1991. Salinity and temperature $\left({ }^{\circ} \mathrm{C}\right),(\mathbf{A}, \mathbf{B})$ at $40 \mathrm{dbar}(\mathbf{C}, \mathbf{D})$ at $120 \mathrm{dbar}$.

(equatorward) heat flux and OI-SST anomaly over Flemish Cap is observed (Fig. 18a). Hence, stronger southward heat flux across $47^{\circ} \mathrm{N}$ over Flemish Cap seems associated with warm events. This feature may appear contradictory if we consider advection by the LC as the primary mechanism determining local thermal variability, and if we expect a link between LC intensity and its particular T-S anomaly. The years 1989 to 1994 have been reported as extremely cold years with temperature anomalies that resembled those of the mid-1970s during the time of the Great Salinity Anomaly. Low temperature in the early 1990s were also observed farther north in the Labrador Sea and in the Davis Strait, and also at the east coast of Greenland and Denmark Strait (Buch, MS 1998). For instance, Buch (MS 1998) reported that over this period waters off southwest Greenland were colder than nor$\mathrm{mal}$ in the upper $400 \mathrm{~m}$. However, salinities during the 1989-94 period were only slightly below normal for the Flemish Cap (Colbourne and Foote, 2000) as well as the Labrador Sea and the east coast of Greenland. Buch (MS 1998) considered both facts as indices of little freshwater input across Denmark Strait together with cold and dry conditions across western Greenland and the Canadian Arctic.

We only have data from 1988-93, but a considerable decline in mean upper layer temperature over Flemish Cap was observed (Fig. 17). This decrease occurred together 

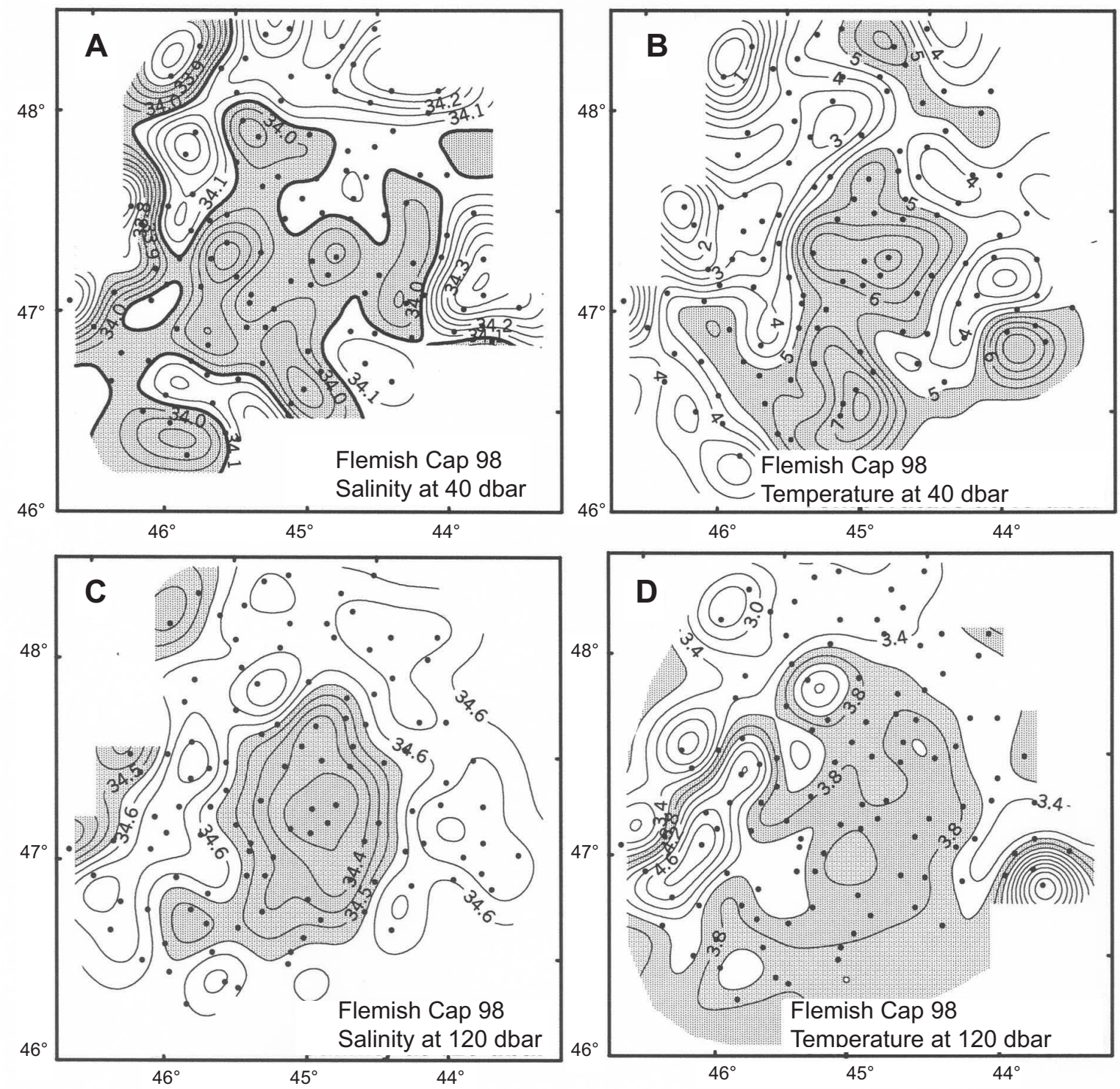

Fig. 10. 1998. Salinity and temperature $\left({ }^{\circ} \mathbf{C}\right),(\mathbf{A}, \mathbf{B})$ at 40 dbar $(\mathbf{C}, \mathbf{D})$ at120 dbar.

with a net poleward export of heat during the cold years to balance the heat deficit to the north. In contrast, the next period 1995-2000 was characterized by an increase in both SST and subsurface temperatures (e.g. Colbourne and Foote, 2000), which was accompanied by null to equatorward net heat flux across the $47^{\circ} \mathrm{N}$ line (Fig. 16b).

Both processes may be linked in a coupled slope water system (CSWS) responding in a similar manner to climate forcing over a broad range of time scales. Two characteristic CSWS modes have been identified over the Northwest Atlantic (Pickart et al., 1999). The maximum mode is characterized by deep and intense convection in the Labrador Sea; a relatively cool, fresh and thick layer of Labrador Sea Water (LSW) is formed; and the volume transport in the Deep Western Boundary Current increases while volume transport in the Labrador Current diminishes. Conversely, the minimum mode corresponds to a system state in which convective renewal of intermediate and deep waters in the Labrador Sea is weaker and shallower; LSW becomes warmer, saltier and thinner and volume transport in the DWBC diminishes while the volume transport in the shallow Labrador Current increases (Dickson et al., 1996; Dickson, 1997; Curry et al., 1998). Heywood et al. (1994) already reported that interannual changes in the LC offshore branch are common. They pointed out that these could be associated with variations in the West Greenland Current. 

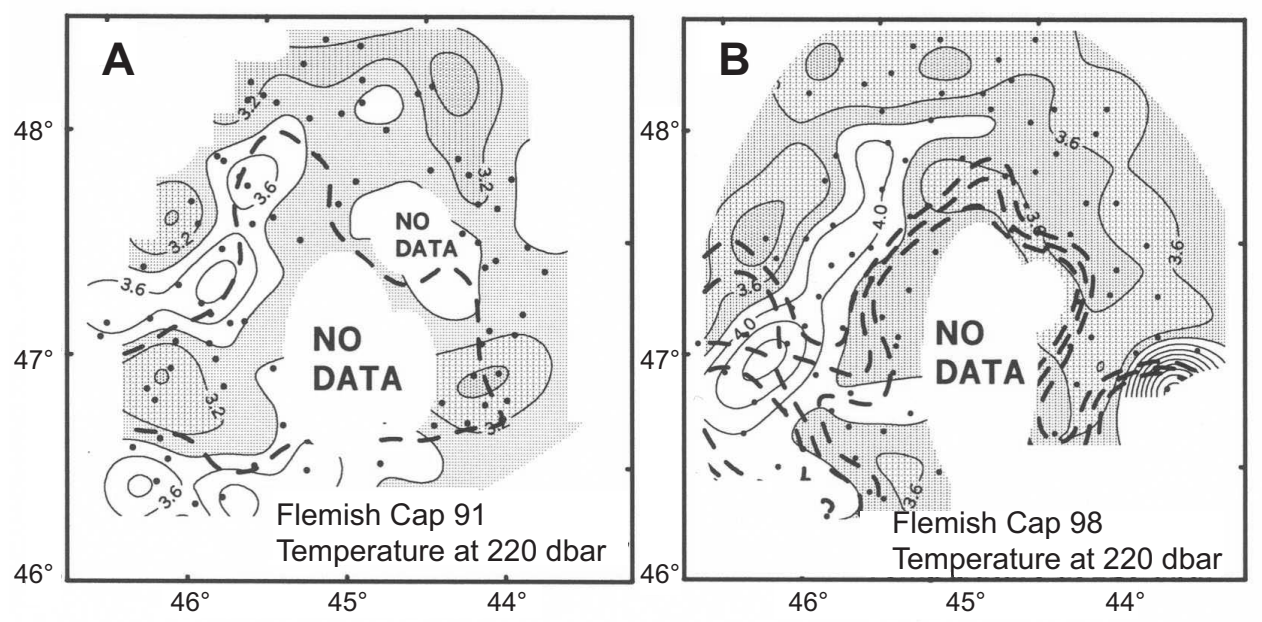

Fig. 11. Temperature $\left({ }^{\circ} \mathrm{C}\right)$ at 220 dbar in (A) July 1991 and (B) July 1991.
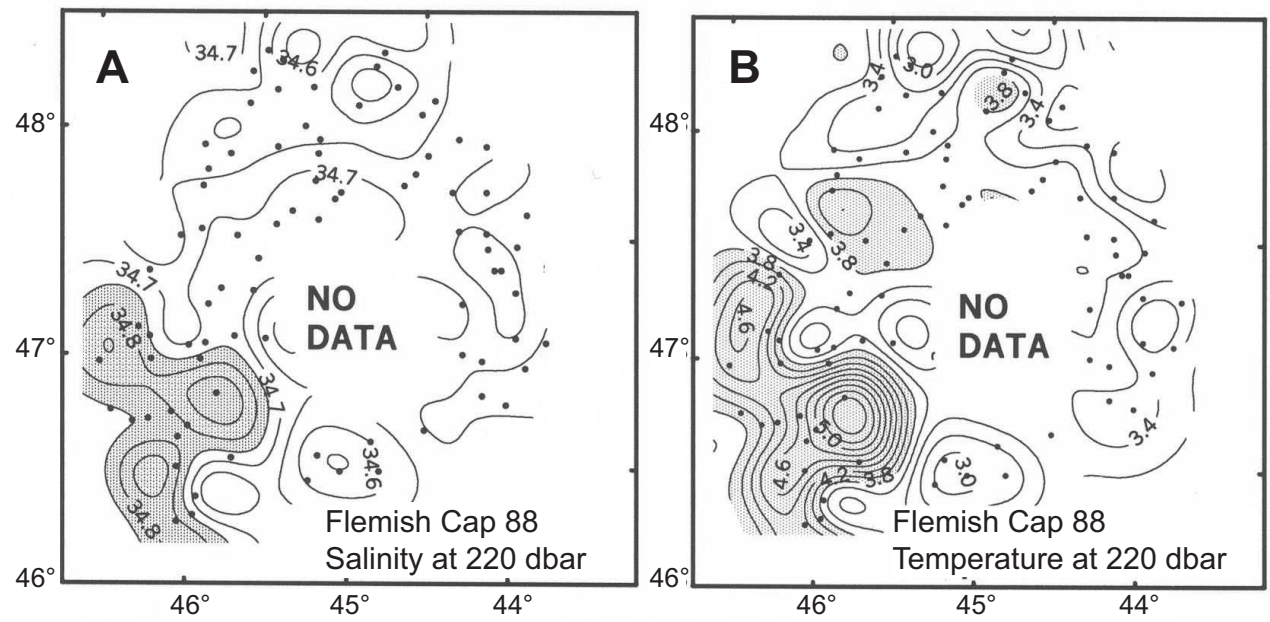

Fig. 12. Salinity and temperature at 220 dbar in July 1988.

Although the linkage is not straightforward it is tempting to associate maximum (minimum) modes of the CSWS with positive (negative) phases of the North Atlantic Oscillation (NAO) (Pickart et al., 1999). Hurrell (2000) discussed that the intensity of the winter convective activity in the North Atlantic is characterized by interannual as well as interdecadal variability that appears to be synchronized with the NAO. The winter (December through March) index of the NAO based on the difference of normalized sea level pressure anomalies between Lisbon, Portugal and Stykkisholmur/Reykjavik, Iceland is presented in Fig. 19. Data presented here are maintained by Jim Hurrell from the National Center for Atmospheric Research (Climate Analysis Section; http://www.cgd. ucar.edu/ jhurrell/nao.html). The atmospheric conditions over the North Atlantic area are highly dominated by the $\mathrm{NAO}$, which has been in a persistent and high positive phase since the early 1980s, but with occasional years with strong negative values such as in the mid-1990s. In the NAO positive phase, higher than normal surface pressures south of $55^{\circ} \mathrm{N}$ combine with a broad region of anomalously low pressure throughout the Arctic, which brings about, among other things, anomalously strong cold northerly flow across western Greenland and the Canadian Arctic, causing descending air temperatures over land and of SSTs over the whole northwest Atlantic (Hurrell, 2003). Intense convective activity in the Labrador Sea in the early 1990s has been documented (e.g. Hurrell, 2003). LSW has become progressively colder and fresher but associated surface LC transports had fallen to 

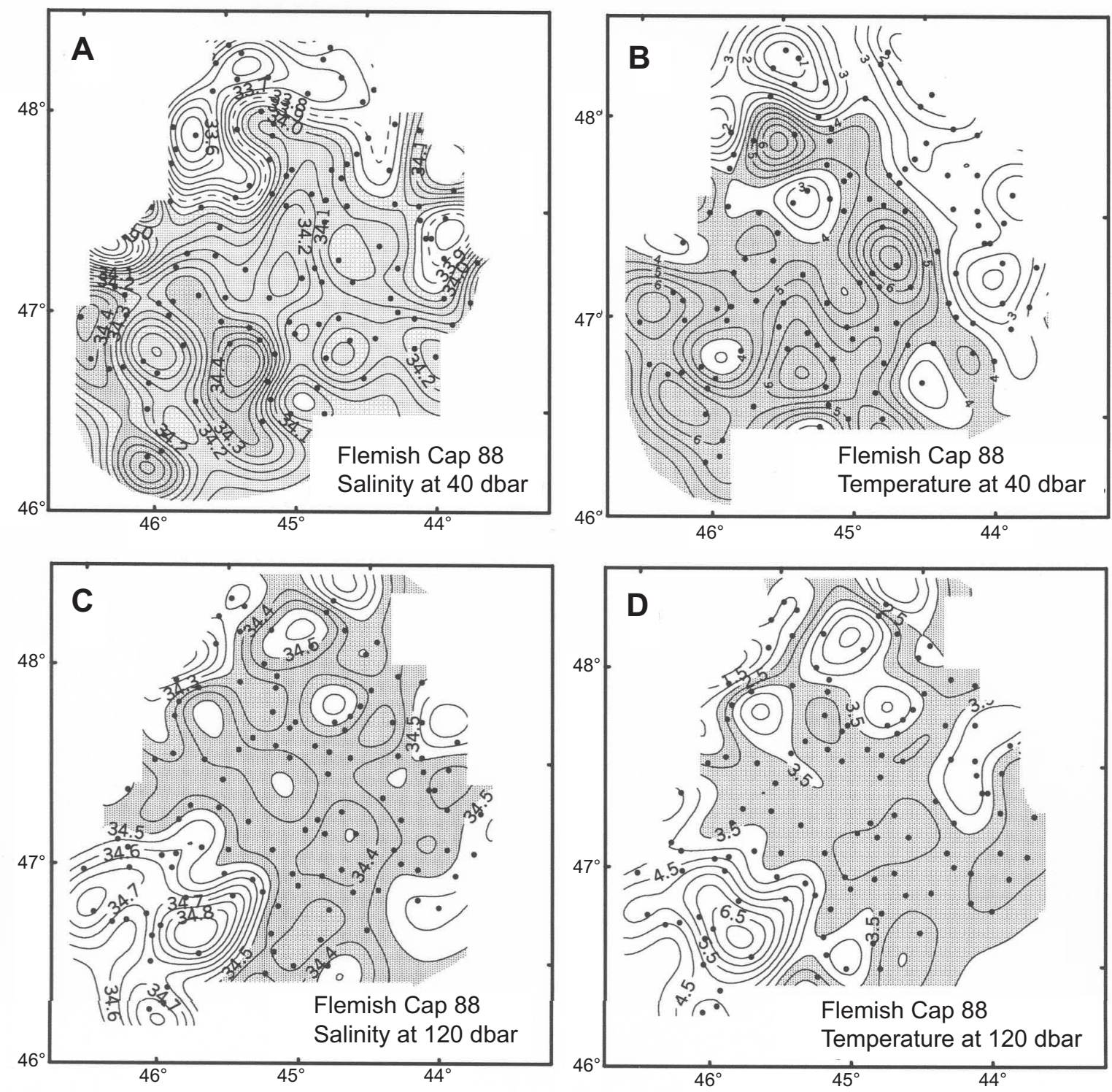

Fig. 13. 1988. Salinity and temperature $\left({ }^{\circ} \mathrm{C}\right),(\mathbf{A}, \mathbf{B})$ at $40 \mathrm{dbar}(\mathbf{C}, \mathbf{D})$ at $120 \mathrm{dbar}$.

a minimum by the mid-1990s as inferred from the heat flux estimates presented here and which belong to a clear maximum CSWS mode.

Conversely, the weakening of the NAO phase after the mid-1990s may be associated with a shift towards a minimum CSWS mode that brings about the formation of a large volume of warmer and saltier LSW. This shift in CSWS is noted at Flemish Cap and brings about the relative increase of both northward/southward components of the heat flux and a tendency towards a net balanced or equatorward heat flux perpendicular to the $47^{\circ} \mathrm{N}$ line across the bank. This, together with the concomitant rela- tive increase of both northward/southward components of the geostrophic volume transport in this five-year period, also indicates a well-developed anticyclonic circulation over Flemish Cap. We conclude that the stronger the Labrador Current, the better the conditions for the development of the anticyclonic gyre anchored on the topography of the bank.

\section{Conclusions and Summary}

The recurrence of the anticyclonic circulation around Flemish Cap in July suggests that the topographic constraint of the bank primarily determines the dynamics over 

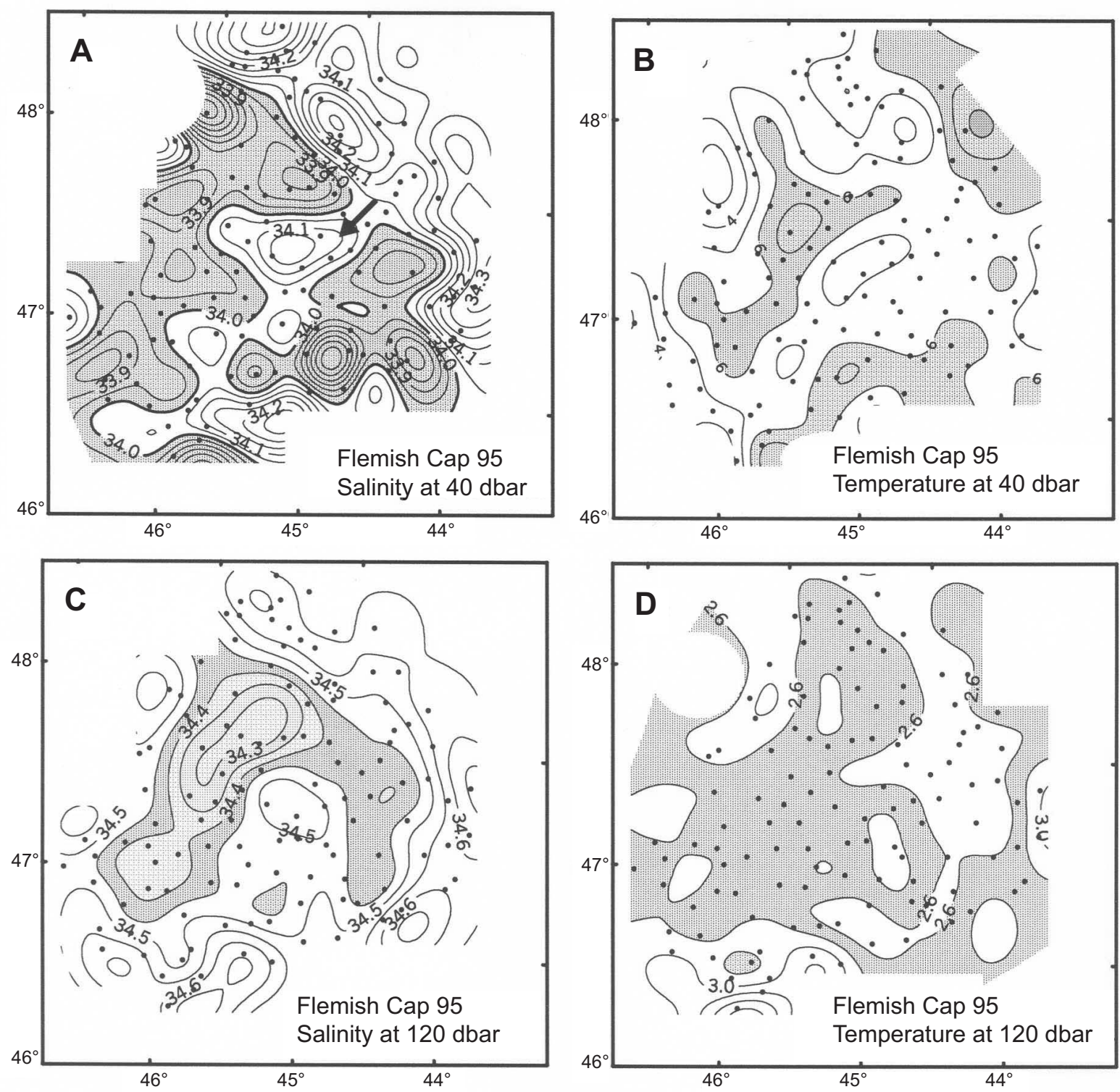

Fig. 14. 1995. Salinity and temperature $\left({ }^{\circ} \mathrm{C}\right),(\mathbf{A}, \mathbf{B})$ at $40 \mathrm{dbar}(\mathbf{C}, \mathbf{D})$ at $120 \mathrm{dbar}$.

the Cap. A coherent cold current skirts around the northeastern flank and partly recirculates around the southern and southwestern flanks forming a central anticyclonic core. This summer circulation is partly responsible for the temperature gradients between the Cap's center and its surroundings. We conclude that the most significant source of variability of the water masses over Flemish Cap was linked to the changes in the advective flows, namely the offshore branch of the $\mathrm{LC}$ and oscillations of the NAC's north wall.
The sampling methodology permitted the intensity and shape of the structures to be fairly well defined. The resulting picture shows a mean asymmetric anticyclonic circulation around the Cap with enhanced southerly geostrophic velocities of $\sim 0.07 \mathrm{~ms}^{-1}$ with respect to the poleward flow of $\sim 0.03 \mathrm{~ms}^{-1}$. From the surface through to the bottom, the gyre generally contains less saline waters than its surroundings. The anticyclonic gyre was particularly well defined in 1998 when isolines nearly closed around the Cap. The occurrence of warm and saline waters along 

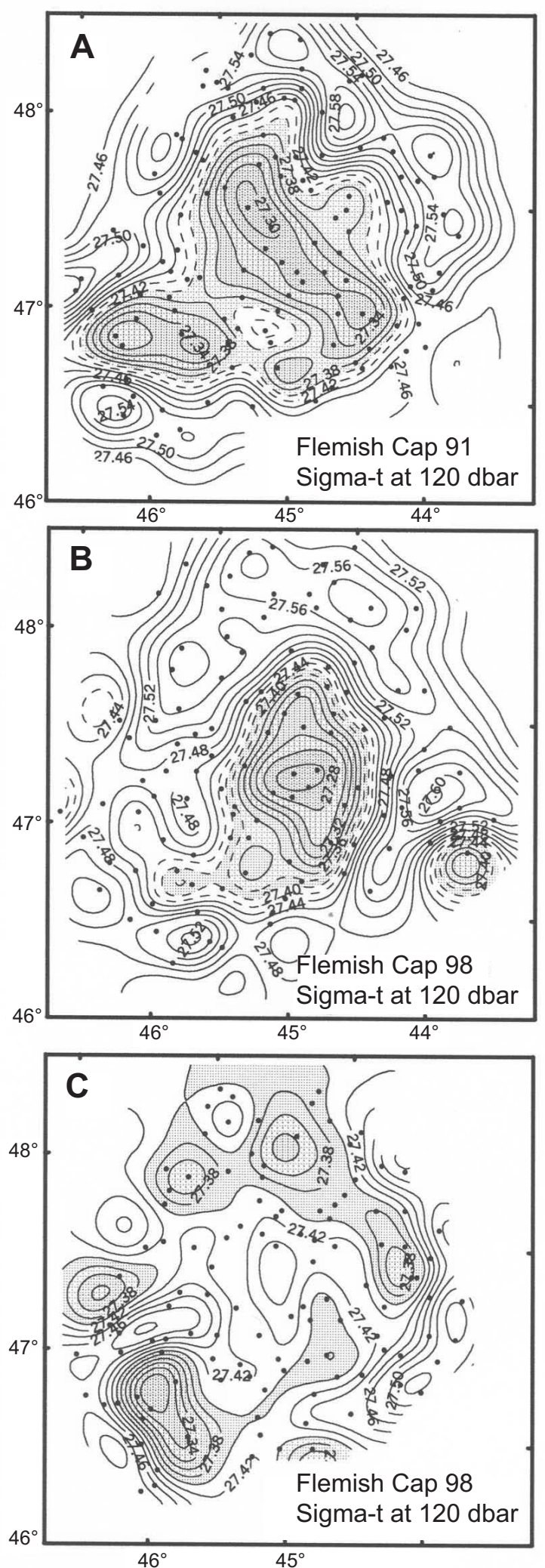

Fig. 15. Sigma-t at 120 dbar in (A) July 1991; (B) July 1998; (C) July 1988. the southern flank of the Cap has also been observed, which may well have their source in subtropical NAC waters. These showed a maximum in 1988 with salinity values above 34.8 and temperatures $\sim 6^{\circ} \mathrm{C}$ at $120 \mathrm{dbar}$.

Results confirm that the anticyclonic circulation on the bank principally arises due to flow of the LC over Flemish Cap. This seems to be a recurrent process but intermittent, as drifting buoy data (e.g. Loder et al., 1988) suggest that their residence times are significantly lower than the recirculation times. Kudlo et al. (1984) suggested that atmospheric storms may act to break up the gyre. We have observed that NAC intrusions may weaken the gyre. The gyre contains less dense waters versus the colder, denser eastern masses. Below $60 \mathrm{db}$ the NAC-sourced waters are extremely warm versus the low salinity, colder waters on the Cap. Subsurface (e.g. $120 \mathrm{db}$ ) densities were observed in some years to be quite similar for both the NAC-type and the anticyclonic gyre waters. In this case, the anticyclonic gyre at this level might be very weak or not exist.

The total northward (positive) and southward (negative) transports across $47^{\circ} \mathrm{N}$ were $\mathrm{O}(0.3) \mathrm{Sv}$ but tended to be higher after 1995. On average, these transports balanced each other resulting in no net flow. The geostrophic heat flux anomalies in each direction were estimated to be order of $2.3 \mathrm{TW}$ and therefore to balance each other, although the long-term trend of the heat flux shifted from weakly northward in the late-1980s to slightly southward in the second half of the 1990s. The first half of the study period (1989-94) was associated with the maximum CSWS mode and characterized by deep and intense convection in the Labrador Sea and reduced volume transport in a colder, fresher Labrador Current. The latter resulted in a generalized drop in the SST over Flemish Cap. There was also a net poleward export of heat during these cold years to balance the heat deficit to the north. The second half of the study period (1995-2000) was characterized by an increase in both SST and subsurface temperatures, which was accompanied by null to southward net heat flux across the $47^{\circ} \mathrm{N}$ line. It was associated with a shift towards a minimum CSWS mode, with weaker convective renewal of intermediate and deep waters in the Labrador Sea and an enhanced warmer, more saline Labrador Current. July SST anomalies and heat flux across the $47^{\circ} \mathrm{N}$ line were seen to be a consequence of the variability of the $\mathrm{LC}$ rather than a consequence of seasonal processes within the retained waters. Intensity of the southward offshore branch of the LC over the bank is concluded to be the primary mechanism determining variability in heat transport across Flemish Cap. 


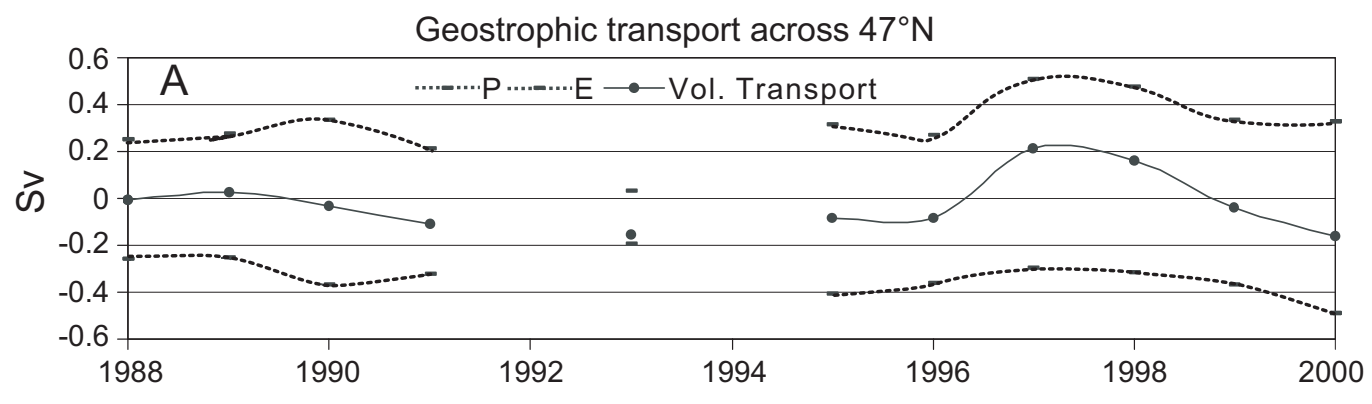

Heat flux across $47^{\circ} \mathrm{N}$

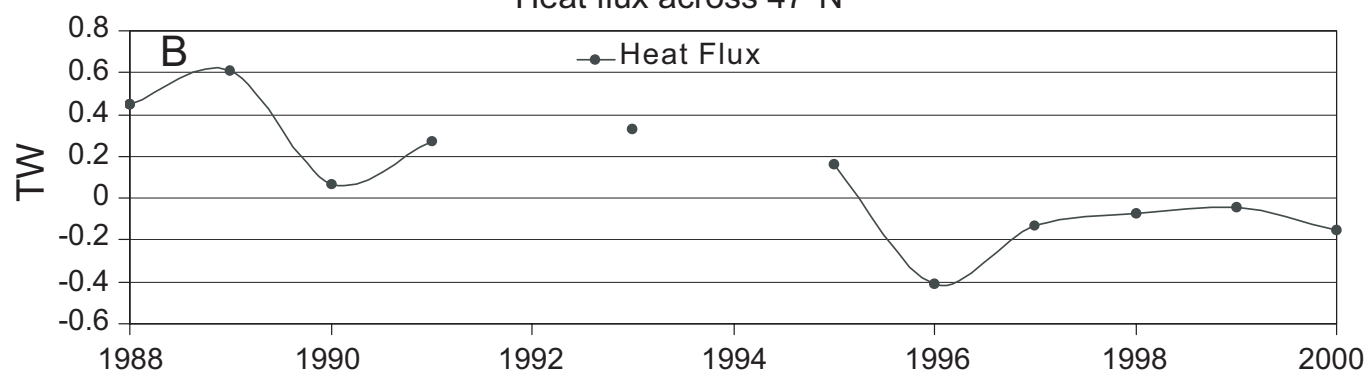

Fig. 16. (A) 1988-2000 geostrophic volume transport (Sv.) $\left(1 \mathrm{~Sv}=10^{6} \mathrm{~m}^{3} \mathrm{~s}^{-1}\right)$ across $47^{\circ} \mathrm{N}$ over Flemish Cap. P stands for poleward and $\mathrm{E}$ for equatorward components of the overall flow. (B) 1988-2000 net heat flux (Terra Watts) $\left(1 \mathrm{TW}=10^{12} \mathrm{~W}\right)$ across $47^{\circ} \mathrm{N}$ over Flemish Cap.

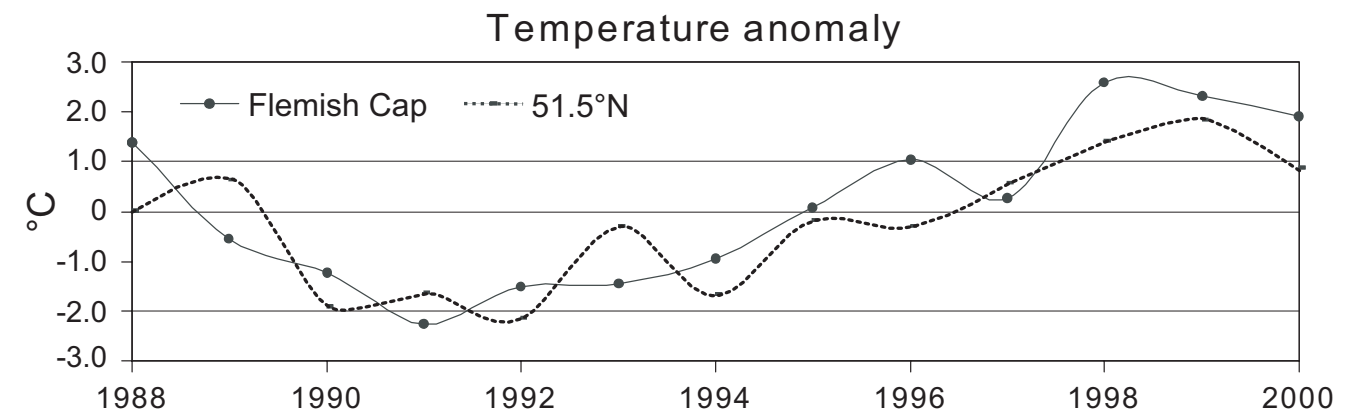

Fig. 17. Optimally interpolated SST (OISST) anomalies $\left({ }^{\circ} \mathrm{C}\right)$ from July 1988 to July 2000 at various locations in the western North Atlantic. Bold line: computed mean over Flemish Cap. Broken line: at $51.5^{\circ} \mathrm{N}$.

The question remains whether the source of LC variability and the shift in the CSWS is linked to the NAO, but this shift in CSWS is noted at Flemish Cap and brings about the relative increase of both northward/southward components of the heat flux and a tendency towards a net balanced or equatorward heat flux perpendicular to the $47^{\circ} \mathrm{N}$ line across the bank. This, together with the relative increase of both northward/southward components of the geostrophic volume transport in this five-year period, would also indicate increased anticyclonic circulation over Flemish Cap. It can be concluded that the stronger the LC the better the conditions for the development of the anticyclonic gyre anchored on the topography of the bank.

\section{Acknowledgements}

The authors would like to thank Ken Drinkwater for his kind help. We are also very grateful to Eugene Colboune and Antonio Vazquez for their encouragement in this work. 

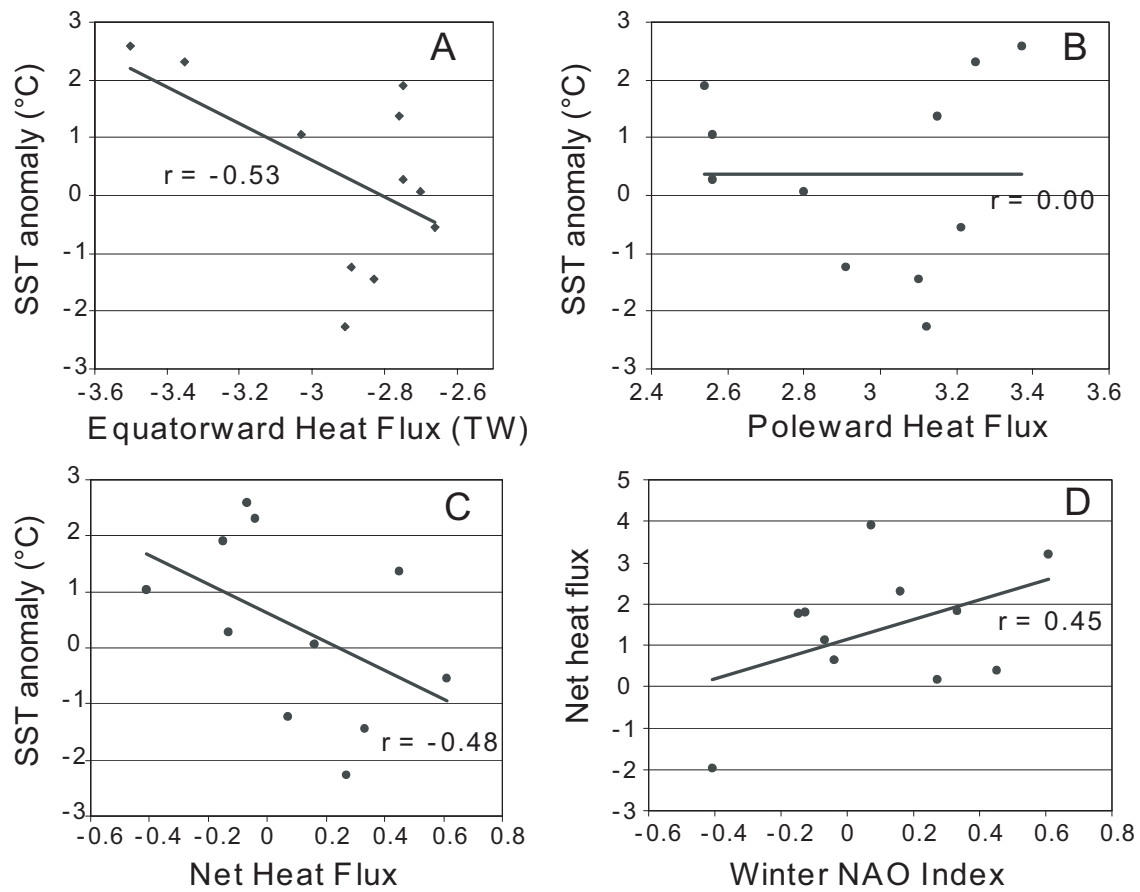

Fig. 18. Scatter plots of: (A) Flemish Cap OISST anomalies $\left({ }^{\circ} \mathrm{C}\right)$ versus equatorward heat flux (TW) across $47^{\circ} \mathrm{N}$ over Flemish Cap; (B) Flemish Cap OISST anomalies $\left({ }^{\circ} \mathrm{C}\right)$ versus poleward heat flux (TW) across $47^{\circ} \mathrm{N}$ over Flemish Cap; (C) Flemish Cap OISST anomalies $\left({ }^{\circ} \mathrm{C}\right)$ versus net heat flux (TW) across $47^{\circ} \mathrm{N}$ over Flemish Cap; (D) net heat flux (TW) across $47^{\circ} \mathrm{N}$ over Flemish Cap versus winter NAO index

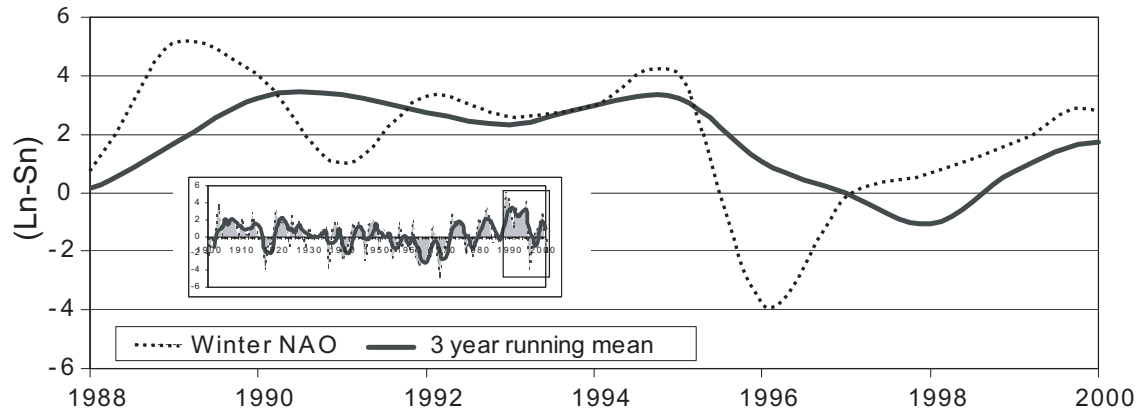

Fig. 19. 1988-2000 winter North Atlantic Oscillation (NAO) index (difference of normalized sea level pressure anomalies between Lisbon, Portugal and Stykkisholmur/ Reykjavik, Iceland). The inset presents the 1900-2000 series. Bold line: 3-year running mean.

\section{References}

ANDERSON, J. T. 1984. Early life history of redfish (Sebastes spp.) on Flemish Cap. Can. J. Fish. Aquat. Sci., 41: 1106-1116.

AKENHEAD, S. A. 1986. Water retention over Flemish Cap. S. Skreslet (ed.) The Role of Freshwater Outflow in Coastal Marine Ecosystems. NATO ASI Series G7, SpringerVerlag, New York, USA, p. 283-293.
BARANOV, E. I., and V. G. GINKUL. 1984. Dynamics of waters of the Newfoundland energy active zone. Meteorogiya di Gidrologiya, 12: 78-84.

BARNES, S. L. 1964. A technique to maximizing details in numerical weather map analyses. J. Appl. Meteor., 3: 396-409.

BOROKOV, V. A, and B. P. KUDLO. MS 1981. Water circulation in the Baffin Land, Labrador, Newfoundland and 
Flemish Cap areas in 1980. NAFO SCR Doc., No. 79, Serial No. N364, 12 p.

BUCH, E. MS 1998. Oceanographic investigations in West Greenland waters, 1981-1997. NAFO SCR Doc., No. 24, Serial No. N3008, 28 p.

CERVIÑO, S., and R. PREGO. MS 1997. Hydrographic Conditions on the Flemish Cap in July 1996. NAFO SCR Doc., No. 17, Serial No. N2847, 13 p.

CERVIÑO, S., R. PREGO, and M. GÓMEZ-GESTEIRA. 1999. New local-scale hydrographic observation on Flemish Cap in July 1996. NAFO Sci. Coun. Studies, 32: 17-24.

COLBOURNE, E. MS 1993. Oceanographic conditions on the Flemish Cap during the summer of 1993, with comparisons to the long-term average. NAFO SCR Doc., No. 93, Serial No. N2300, 36 p.

1995. Oceanographic conditions on the Flemish Cap during the summer 1995, with comparisons to the 1961-1990 average. NAFO SCR Doc., No. 102, Serial No. N2625, 12 p.

MS 1996. Oceanographic conditions on the Flemish Cap during the summer 1996, with comparisons to the previous year and the 1961-1990 average. NAFO SCR Doc., No. 96, Serial No. N2770, 16 p.

MS 1997. Oceanographic conditions on the Flemish Cap during the summer of 1997, with comparisons to the previous year and the 1961-1990 average. NAFO SCR Doc., No. 84, Serial No. N2930, 15 p.

COLBOURNE, E., and K. D. FOOTE. 2000. Variability of the stratification and circulation on the Flemish Cap during the decades of 1950s and 1990s. J. Northw. Atl. Fish Sci., 26: $103-122$.

CURRY, R. G., M. S. McCARTNEY, and T. M. JOYCE. 1998. Oceanic transport of subpolar climate signals to mid-depth subtropical waters. Nature, 388: 575-577.

DAVIS, P. A. 1972. Experiments on Taylor columns in rotating stratified fluid. J. Fluid Mech., 54: 691-717.

DICKSON, R. 1997. From the Labrador Sea to global change. Nature, 386: 649-650.

DICKSON, R., J. LAZIER, J. MEINKE, P. RHINES, and J. SWIFT. 1996. Long-term coordinate changes in the convective activity of the North Atlantic. Progr. Oceanogr., 38: 241-295.

DOSWELL, C. A. 1977. Obtaining meteorologically significant surface divergence fields through the filtering property of objective analysis. Mon. Wea. Rev., 105: 885-892.

FOFONOF, N. P., and R. M. HENDRY. 1985. Current variability near the southeast Newfoundland Ridge. J. Phys. Oceanogr., 15: 963-984.

FREELAND, H. 2002. The heat flux across Line-P 1996-1999. Atmosph.-Ocean, 40: 81-89.

GIL, J., R. F. SÁNCHEZ, M. BLANCO, and I. REGUERA. MS 1998. Hydrodynamics associated to the confluence of Labrador and North Atlantic currents over Flemish Cap in July 1997. NAFO SCR Doc., No. 32, Serial No. N3019, 11 p.

GREENBERG, D. A., and B. D. PETRIE. 1988. The mean barotropic circulation on the Newfoundland Shelf and Slope. J. Geophys. Res., 93: 15541-15550.

HAYES, R. M., D. G. MOUNTAIN, and T. C. WOLFORD. MS 1977. Physical oceanography and the abiotic influence on cod recruitment in the Flemish Cap region. ICNAF Res. Doc., No. 54, Serial No. 5107, 33 p.

HEYWOOD, K. J., E. L. M'DONALD, and M. A. WHITE. 1994. Eddy kinetic energy of the North Atlantic subpolar gyre from satellite altimetry. J. Geophys. Res., 99: 22 525-22539.

HOGG, N. G. 1973 The preconditioning phase of MEDOC 1969. Part II: topographic effects. Deep-Sea Res., 20: 449-459.

HUPPERT, H. E. 1975. Some remarks on the initiation of inertial Taylor Columns. J. Fluid Mech., 67: 397-412.

HUPPERT, H. E., and K. BRYAN. 1976. Topographically generated eddies. Deep-Sea Res., 23: 655-679.

HURRELL, J. W. 2003. Climate: North Atlantic and Arctic Oscillation (NAO/AO). In: Encyclopedia of Atmospheric Sciences. J. Holton, J. Pyle, and J. Curry (eds.). Academic Press., p. 439-445.

JACOBS, S. J. 1964. The Taylor column problem. J. Fluid Mech., 20: 581-591.

KARASYEV, B. E. MS 1962. Hydrologic investigations carried out aboard the vessel of the Kaliningrad Council for People's Economy in 1961 in ICNAF Subareas 2 and 3. ICNAF Res. Doc., No. 71, Serial No. 1014, 10 p.

KRAUSS, W., E. FAHRBACH, A. AITSAM, J. ELKEN, and P. KOSKE. 1987. The North Atlantic Current and its associated eddy field southeast of Flemish Cap. Deep-Sea Res., 34: 1163-1185.

KUDLO, B. P., and B. A. BOROKOV. MS 1975. Circulation of waters in the ICNAF area in 1974-75. ICNAF Res. Doc., No. 79, Serial No. 3874, 14 p.

KUDLO, B. P., and V. V. BURMAKIN. MS 1972. Water circulation in the south Labrador and Newfoundland areas in 1970-71. ICNAF Redbook, Vol. III: 27-33.

KUDLO, B. P., B. A. BOROKOV, and N. G. SAPRONETSKAYA. 1984. Waters circulation pattern on Flemish Cap from observations in 1977-82. NAFO Sci. Coun. Studies, 7: $27-38$

LAZIER, J., and D. WRIGHT. 1993. Annual velocity variations in the Labrador Current. J. Phys. Oceanogr., 23: 659-678.

LODER, J. W., C. K. ROSS, and P. C. SMITH. 1988. A spaceand time-scale characterization of circulation and mixing over submarine banks, with application to the Northwestern Atlantic continental shelf. Can. J. Fish. Aquat. Sci., 45: $1860-1885$.

LOZIER, M. S., W. B. OWENS, and R. G. CURRY. 1995. The climatology of the North Atlantic. Progr. Oceanogr., 36: $1-44$.

MADDOX, R.A. 1980. An objective technique for separating macroscale and mesoscale features in meteorological data. Mon. Wea. Rev., 108: 1108-1121.

NODC. 2000. World Ocean Database 1998. Documentation and quality control. Version 2.0. Ocean Climatic Lab. NODC Internal Report No. 14. Silver Spring MD. (http://www. nodc.noaa.gov/oc5/pr_wodv2.html).

PETRIE, B., and C. ANDERSON. 1983. Circulation on the Newfoundland Shelf. Atmosph.-Ocean, 21: 207-226.

PETRIE, B. and J. BUCKLEY. 1996. Volume and freshwater transport of the Labrador Current in Flemish Pass. J. Geo- 
phys. Res., 101: 28335-28342.

PICKART, R. S., T. K. McKEE, D. J. TORRES, and S. A. HARRINGTON. 1999. Mean structure and interannual variability of the slope water system south of Newfoundland. J. Phys. Oceanogr., 29: 2541-2558.

PROUDMAN 1916. On the motion of solids in liquids possessing vorticity. Proc. Roy. Soc., Ser. A, 92: 408-424.

ROBE, R. Q. MS 1974. Circulation east of the Grand Banks, 1973. + Addendum. ICNAF Res. Doc., No. 107, Serial No. N3345, 1 p. +8 p. addendum.

ROSS, C.K. 1981. The drift of satellite-tracked buoys on Flemish Cap, 1979-80. NAFO Sci. Coun. Studies, 1: 47-50.

SMITH, E. H., F. M. SOULE, and O. MOSBY. 1937. The Marion and General Green expeditions to Davis Strait and the
Labrador Sea. Bull. U.S. Coast Guard, 19: 259 p.

TAYLOR, G.I. 1923. Experiments on the motion of solid bodies in rotating fluids. Proc. R. Soc. London, Ser. A, 104: 213-218.

TEMPLEMAN, W. MS 1974. Temperature and salinities in the eastern Newfoundland area in 1973. ICNAF Res. Doc., No. 71, Serial No. 5104, 13 p.

UNESCO. 1991. Processing of oceanographic station data, 1991. JPOTS editorial panel.

VÁZQUEZ, A. MS 2000. Results of the bottom trawl survey on Flemish Cap of July 1999. NAFO SCR Doc., No. 9, Serial No. $4228,50 \mathrm{p}$.

WORTHINGTON, L.V. 1976. On the North Atlantic circulation. The Johns Hopkins Oceanographic Studies, 6: 110 p. 
